\title{
Uncertainty in an emerging market economy: evidence from Thailand
}

\author{
Tosapol Apaitan ${ }^{1} \cdot$ Pongsak Luangaram² $\cdot$ Pym Manopimoke ${ }^{3}$
}

Received: 17 April 2020 / Accepted: 2 April 2021 / Published online: 24 May 2021

(c) The Author(s), under exclusive licence to Springer-Verlag GmbH Germany, part of Springer Nature 2021

\begin{abstract}
This paper constructs various measures of domestic and global uncertainty and provides a comprehensive study of their impacts on the Thai economy. Based on a small open economy VAR, global uncertainty delivers deeper and more long-lasting effects when compared to within-country ones. In addition, we find that uncertainty shocks first generate sudden and large declines for stock prices and foreign portfolio investment, before gradually affecting the real economy through investment and trade channels. There is also meaningful heterogeneity among different types of domestic uncertainty. While financial uncertainty matters most for the Thai economy overall, consumption demand largely responds to macroeconomic uncertainty, while economic policy and political uncertainty generates the most persistent effects on investment. Furthermore, fiscal policy uncertainty is a key driver of trade flows while monetary policy uncertainty plays an important role for capital markets.
\end{abstract}

Keywords Economic · Financial · Political · Policy · News-based · Uncertainty · Emerging market $\cdot$ Small open economy $\cdot$ Spillovers

\footnotetext{
We would like to thank Patcharaporn Leepipatpiboon and Chaitat Jirophat for excellent research assistance. We also appreciate insightful and constructive comments by two anonymous referees. The views expressed in this paper are of the authors and do not necessarily reflect those of the Bank of Thailand.

$\bowtie \quad$ Pym Manopimoke

PymM@bot.or.th

Tosapol Apaitan

TosapolA@bot.or.th

Pongsak Luangaram

Pongsak.L@chula.ac.th

1 Monetary Policy Department, Bank of Thailand, Bangkok, Thailand

2 Faculty of Economics, Chulalongkorn University, Bangkok, Thailand

3 Puey Ungphakorn Institute for Economic Research, Bank of Thailand, Bangkok, Thailand
} 
JEL Classification D80 $\cdot$ E20 $\cdot$ E32 $\cdot$ E44 $\cdot$ E66 $\cdot$ F10 $\cdot$ F30

\section{Introduction}

What are the effects of uncertainty on the economy? Since the global financial crisis, this question has gained widespread attention in the academic literature and sparked numerous policy debates. In advanced economies, policymakers often cite heightened levels of uncertainty as a key factor to the Great Recession and its subsequent weak recovery (FOMC 2009; Balta et al. 2013). Against the backdrop of rapid globalization in trade and financial markets, growing concerns have been voiced regarding the spillover effects of economic and policy uncertainty in advanced countries toward the boom-bust cycle of emerging market economies (EMEs). Global uncertainty has also been recognized as a significant driver of large fluctuations in world asset prices and cross-border financial flows (IMF 2013; Rey 2013; Berger et al. 2016).

A key challenge in studying the effects of uncertainty is that uncertainty is not directly observable. This makes it difficult to measure as well as differentiate between the many types of uncertainty, which include for example, macroeconomic, financial, and geopolitical uncertainty. Nevertheless, the countercyclical effects of uncertainty on the macroeconomy has been well documented. This includes measures of uncertainty based on realized or implied financial market volatility (Bloom 2009; Basu and Bundick 2017), disagreement among professional forecasters (Bachmann et al. 2013), frequency of uncertainty-related keywords in newspaper articles or searches on the Internet (Baker et al. 2016; Castelnuovo and Tran 2017) and forecast errors from macroeconomic and financial data (Jurardo et al. 2015; Rossi and Sekhposyan 2015; Scotti 2016; Carriero et al. 2018a). Recent additions also find nonlinear effects in the transmission of uncertainty shocks, whereby the impact of uncertainty is found to be stronger during crises periods (Caggiano et al. 2014; Alessandri and Mumtaz 2019; Caggiano et al. 2017, 2020; Angelini et al. 2019).

Despite extensive research on this topic, the bulk of the literature focuses heavily on the experiences of advanced economies. As a result, little is still known about the role that uncertainty plays in EMEs. ${ }^{1}$ However, among the few studies that investigate the role of uncertainty shocks in EMEs, large and detrimental effects have been reported, with magnitude depending on various factors such as its economic structure, openness to trade, and policies in place. For example, Miescu (2019) finds that across 15 small EMEs, the dynamic response to domestic uncertainty shocks are sizable, particularly for financial variables, with countries that are less wealthy and more open to trade being the most vulnerable. Focusing on the impact of US uncertainty shocks, Bhattarai et al. (2020) show that EMEs of different regions respond in different ways, with the spillover effect heavily dependent on the stance of monetary policy. Compared to advanced economies, Carrière-Swallow and Cèpedes (2013) and Chatterjee (2018, 2019) argue that emerging countries experience deeper and more prolonged declines in real activity variables in response to global uncertainty shocks due to reasons such as

\footnotetext{
1 In large part, this is due to the lack of long samples and reliable data for these countries. Uncertainty indicators proposed in the literature are also only mainly available for the US and few other developed economies. See www.policyuncertainty.com.
} 
stronger credit constraints in the face of shallow financial markets. Cerda et al. (2018) conduct a single-country analysis for Chile and find that as a small open economy, increases in uncertainty deliver relatively large declines for real economic activity, even in the long run.

To gain a deeper understanding about how uncertainty shocks matter for EMEs, this paper investigates the effects of uncertainty for Thailand. Thailand is chosen as case study for two main reasons. First, it is a small open economy that is highly susceptible to external shocks, making it a natural candidate to analyze the effects of global uncertainty shocks, especially in terms of their importance vis-à-vis domestic uncertainty shocks. Moreover, Thailand has weathered various types of uncertainty shocks over past decades, such as those political in nature which has led itself to episodes of protesting, political coups and constitutional reform. This allows us to perform a comprehensive analysis on how uncertainty shocks of different types can impact an EME, where we study their range of effects on both macro and financial aggregates that also include open economy variables such as exchange rates and trade flows. Our analysis relies on constructing 11 different measures of domestic and global uncertainty measures for Thailand, which we gather from the literature as well as constructing new measures of our own. In doing so, we apply the model-based approach of Jurardo et al. (2015) as well as the newspaper-based approach of Baker et al. (2016). Their dynamic impact on the economy is then investigated in a standard small open economy structural VAR.

The main motivation for our work is based on the premise that past studies often focus on analyzing the effects of only a particular type of uncertainty shock on a single or few activity measures, making it difficult to draw any comparisons across uncertainty shocks of different types and their impact on varying segments of the economy. In this regard, our work offers at least three main contributions to the literature. First, to our knowledge, ours will be the first paper that constructs as well as compares the effects of the most number of types of uncertainty within a consistent and unified framework. We analyze the impact of global, macroeconomic, financial, economic policy and political uncertainty including its key subcomponents, such as monetary policy, fiscal policy, financial uncertainty from credit versus capital markets and macroeconomic uncertainty pertaining to growth outlook versus prices of commodities and agricultural products. While a small literature has started to highlight the heterogeneity that exists between different types of uncertainty, their comparison is still limited to uncertainty measures of only few types, namely macroeconomic versus financial (Redl 2017; Ludvigson et al. forthcoming), subcomponents of policy uncertainty (Mumtaz and Surico 2018), or real versus financial (Cesa-Bianchi et al. 2018).

Second, to gain a deeper understanding on how uncertainty shocks transmits through various channels, we investigate the effects of uncertainty on a wide range of macro and financial variables. Theoretically, uncertainty has been shown to work through investment (Bernanke 1983; McDonald and Siegel 1986; Bloom 2009), consumption (Kimball 1990; Carroll 1997), employment (Leduc and Liu 2016; Guglielminetti 2016) as well as financial (Caldara et al. 2016; Christiano et al. 2014; Gilchrist et al. 2014) and trade channels (Handley and Limão 2012; Handley 2014; Novy and Taylor 2014), but past empirical work often studies their transmission mechanisms separately. In 
this paper, we offer a comprehensive analysis on how uncertainty transmits through various macroeconomic and financial channels, offering results that should prove helpful toward policymakers in being able to appropriately monitor rising uncertainty and manage macro and financial conditions in key sectors.

Finally, we contribute to a fast growing literature on the cross-border effects of global uncertainty shocks. Theoretically, foreign uncertainty shocks from major economies can transmit to small open economies through channels such as global banks or cross-border lending (Fernàndez-Villaverde et al. 2011; Benigno et al. 2012; Luk 2017). Empirically, cross-border effects of uncertainty shocks that originate from the US have been shown to be significant drivers of important economic variables for the UK (Mumtaz and Theodoridis 2015), Europe (Colombo 2013), China (Huang et al. 2018), Hong Kong (Luk et al. 2017) and Australia (Moore 2017), and in most cases, they even dominate the effects of local uncertainty shocks. Recent studies have also shown that global uncertainty, as measured by the common component of the variance of a large set of international financial and macroeconomic variables, can exert significant impacts on key macro and financial variables in developed countries (Berger et al. 2016; Mumtaz and Theodoridis 2017; Carriero et al. 2018a; Mumtaz and Musso 2018; Cuaresma et al. 2019; Kang et al. 2019). To our knowledge, our paper will be the first to offer empirical evidence on the impact of global compared to domestic uncertainty shocks for a small open EME.

As a preview of our results, we find that the impacts of rising uncertainty on real and financial activity in Thailand are contractionary and significant in magnitude. Nevertheless, we do not find the impact of uncertainty for a small open EME like Thailand to be much larger than that of advanced economies. However, we offer novel insight regarding the heterogeneity of uncertainty shock effects through the various channels of transmission. First, in terms of both magnitude and persistence, the impact of global uncertainty shocks dominates those that stem from within country, with global shocks mattering the most for financial markets and trade flows. Second, among domestic uncertainty shocks, while we find that financial uncertainty plays the most prominent role for the Thai economy as a whole, macroeconomic uncertainty pertaining to prices of commodities and domestic markets deliver a relatively large impact on consumption, and macroeconomic uncertainty on production and growth outlook is a more important driver of movements in stock prices. Economic policy uncertainty plays a rather muted role overall, although fiscal policy matters to large extent for trade flows, and monetary policy uncertainty for capital markets. Finally, we find that uncertainty is a key driver of economic and financial market fluctuations at business cycle frequencies. Global uncertainty shocks, for example, can explain up to $45 \%$ of the variation in the Thai stock market index, while domestic macroeconomic and financial uncertainty are capable of explaining more than $25 \%$ of the fluctuations in investment.

The remainder of the paper is organized as follows. Section 2 provides an overview of the methods we adopt to construct various types of uncertainty measures for Thailand along with analyzing their overall properties. Section 3 describes the data and empirical set up, while Sect. 4 discusses the impact of the different types of uncertainty shocks on the various segments of the economy, and discusses the role of uncertainty 
as an important driver of fluctuations in real economic activity and financial markets. Section 5 concludes.

\section{Measuring uncertainty}

Uncertainty is inherently unobservable and manifests itself in many forms; thus, its measurement is a challenging task. Earlier measures of uncertainty are mostly financial-based, made popular by the influential work of Bloom (2009), whom advocated the use of implied and realized stock market volatilities. However, these measures have been criticized on the grounds that it may also be capturing changes in sentiment or risk aversion of investors. Subsequent studies also propose measuring uncertainty from the cross-sectional dispersion of survey-based forecasts (Bachmann et al. 2013). Survey measures, however, have been shown to be an imperfect proxy for evaluating uncertainty (see Rich and Tracy 2010; Abel et al. 2016) and are often constructed based on a single economic indicator, making it difficult to generalize to the aggregate economy.

More recently, there has been a growing number of improved measures of uncertainty. For example, Jurardo et al. (2015) (hereafter JLN) introduced a broad-based measure of aggregate uncertainty, extracted from a large number of macroeconomic and financial time series based on a diffusion index and stochastic volatility models. The model defines uncertainty as the common variability in the purely unforecastable component of the future value of these variables; thus, unlike previous measures, it appropriately captures uncertainty as the second rather than first moment shock. ${ }^{2}$ Another well-known approach is based on textual analysis. Baker et al. (2016) (hereafter BBD) propose a novel economic policy uncertainty (EPU) measure from the frequency count of 'uncertainty-related' keywords in newspaper articles.

In this section, we apply JLN and BBD approaches to construct five broad types of uncertainty measures that are highly relevant to the Thai economy: (i) global economic uncertainty; (ii) Thai macroeconomic uncertainty; (iii) Thai financial uncertainty; (iv) Thai political uncertainty; and (v) Thai economic policy uncertainty. Within each of these broad classes, we also consider subcategory measures. For example, our macroeconomic uncertainty measure can be decomposed into components that relate to growth outlook versus prices; financial uncertainty is comprised of capital markets and credit markets; and economic policy uncertainty can be divided into parts that are related to monetary or fiscal policies. Altogether, we consider 11 measures of uncertainty for Thailand, in which we gather from disparate sources in the literature as well as construct new measures of our own by applying JLN and BBD approaches to Thai data. We provide an overview of the measurement approaches below as well as a detailed analysis of our constructed uncertainty measures.

\footnotetext{
2 This is a distinction that earlier measures of uncertainty such as survey-based ones often fail to address. First moment shocks can be thought of as a deterioration in the expected outcome which is not uncertainty, just bad news. Second moment shocks on the other hand are uncertainty and are defined as a greater range of expected outcomes. Disentangling the two can be difficult, especially since market participants tend to become more pessimistic in the face of greater uncertainty.
} 


\subsection{Model-based uncertainty}

JLN proposes a methodology to measure aggregate uncertainty for the US economy as the conditional variance of the unforecastable component common to a large number of macroeconomic and financial variables. Their measure is based on the premise that what matter for agents' decisions is not whether particular economic indicators have become more or less variable or disperse, but whether the economy has become more or less predictable. In this way, their measure of uncertainty is defined as a deterioration in predictability. Also, in contrast to previous measures of uncertainty that is often based on a single (or a few) economic indicators, JLN's measure is common to a large set of economic time series that spans many markets and segments.

Following JLN, several studies construct measures of aggregate uncertainty for countries in the Euro area (see Redl 2017; Meinen and Roehe 2017). In this paper, we apply the JLN methodology to construct aggregate measures of uncertainty for Thailand. We construct two types of aggregate uncertainty measures-macroeconomic and financial. For both measures, we compute uncertainty for four quarter-ahead forecasting horizons. The underlying dataset for these indices comprises of quarterly macroeconomic and financial data obtained from the Bank of Thailand and the Stock Exchange of Thailand databases. In total, they cover 199 macroeconomic series that represent broad categories that describe the macroeconomy and 22 financial series. While readers should refer to JLN for full details of the econometric approach, the authors' methodology along with details of our dataset is briefly summarized in Appendix A.

The resulting macroeconomic and financial uncertainty indices are plotted in Fig. 1 in comparison with the original US macroeconomic and financial uncertainty indices produced by JLN (in standardized scale). Overall, financial uncertainty appears slightly more volatile, which is not surprising given that financial variables are generally known to exhibit more variability. Particularly, Thai financial uncertainty heightened significantly during the global financial crisis (GFC) in 2008, the Euro area sovereign debt crisis in 2011 and the Fed's Taper Tantrum in 2013, while domestic macroeconomic uncertainty also captured the GFC episode and displayed a second peak during the second half of 2011. During this period, Great floods in Thailand led to severe disruptions in supply chains and production sectors.

It is interesting to see that both Thai macroeconomic and financial uncertainty measures exhibit a strong correlation with the JLN's US macroeconomic uncertainty (71\%) and US financial uncertainty (76\%). This observation suggests potential spillovers of US uncertainty shocks to a small open economy like Thailand. Based on the JLN methodology, Londono et al. (2019) also construct real economic uncertainty indicators for G-7 and Switzerland and observe that the evolution of uncertainty from the US and other advanced economies tends to move together, especially during recession episodes. However, Ahir et al. (2021) show that the source of spillover comes from only a few countries. By applying textual analysis to the Economist Intelligence Unit country reports (covering 143 countries), the authors study uncertainty spillovers from G7 economies plus China to the rest of the world. They find that uncertainties originating in the US and the UK have a strong spillover effect than other large economies, 


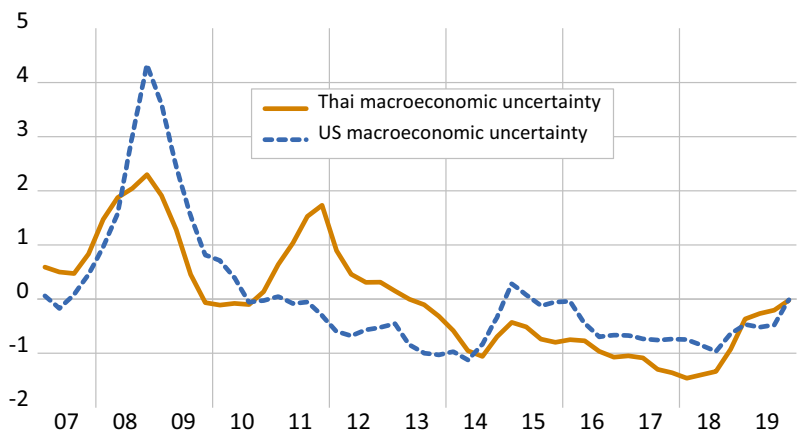

(a) Macroeconomic Uncertainty

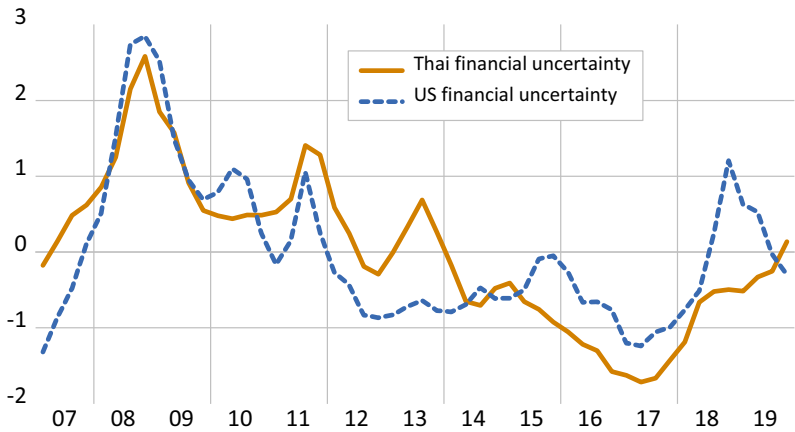

(b) Financial Uncertainty

Fig. 1 Model-based macroeconomic and financial uncertainties. a Macroeconomic uncertainty. b Financial uncertainty. Note Plotted are Thai and US macroeconomic and financial uncertainty indices in standardized scale, constructed by the Jurardo et al. (2015) model-based approach

which play only a relatively minor role. This finding provides justification for our use of US uncertainty as one of the proxies for global uncertainty which we discuss in more detail at a later stage in this section.

\subsection{News-based uncertainty}

In the seminal work of BBD, the authors aim to capture 'economic policy uncertainty' along three dimensions: "uncertainty about who will make economic policy decisions, what economic policy actions will be undertaken and when, and the economic effects of policy actions (or inaction)..." (p. 1598). To do so, they propose a novel approach to compute US economic policy uncertainty (EPU) based on a frequency count of news stories that are related to uncertainty about economic policy. It is assumed that greater news coverage on specific policy issues would indirectly indicate higher degrees of uncertainty surrounding those topics. The index is based on a Boolean search using predetermined keywords by counting articles in leading US newspapers that contain the key terms "economic" or "economy"; "uncertain" or "uncertainty" and selected 
policy terms such as "congress," "deficit" and the "Federal Reserve." Following BBD, many studies have constructed news-based uncertainty indices for the Euro area and other advanced economies. EPU indices for advanced Asian economies also exist, including those for China, Japan, Australia and Hong Kong (see Baker et al. 2013; Luk et al. 2017; Moore 2017; Arbatli et al. 2019). These news-based uncertainty measures can be found at http://www.policyuncertainty.com, which also includes a global economic policy uncertainty (GEPU) index which is a GDP-weighted average of national EPU measures across 21 countries (Davis 2016).

In this paper, we aim to apply the BBD methodology to not only capture uncertainty in Thailand that is related to economic policy, but also other types of uncertainty that are discussed in the news as well. Therefore, we follow Azqueta-Gavaldon (2017) by employing the latent Dirichlet allocation (LDA) method, an unsupervised machine learning algorithm popularized by Blei et al. (2003) to help uncover the underlying topics in the full newspaper corpus. LDA is a generative statistical model which assumes that words are an important element for revealing a topical content covered in the text. The underlying concept rests on the premise that the document (here newspaper article) is simply a combination of multiple topics in different proportions, with each topic being a mixture of words that appear with different probabilities. ${ }^{3}$ One key advantage of this unsupervised learning method over the simple Boolean search adopted by BBD is that topic classification can be found without the need to find suitable keywords for the various types of uncertainty. This makes the approach less costly and more flexible, while at the same time being able to produce reliable results. In fact, Azqueta-Gavaldon (2017) shows that the index constructed with the LDA method is able to produce a measure that matches closely with BBD's original US EPU index. While the LDA method has been adopted to produce uncertainty indices for other countries as well, such as for Norway (Larsen 2021), to our knowledge our paper will be the first to adopt this method toward producing a set of news-based economic uncertainty measures for a small developing country in Asia.

To construct news-based uncertainty for Thailand, we use four local newspapers in Thai language (three leading general newspapers and one main business newspaper). ${ }^{4}$ Unfortunately, the news database sample is rather short and begins in June 2006. Although a longer sample exists for English-based news archives from Bloomberg and the Bangkok Post, we opt to use the Thai news archive because unlike the English one, we have access to all the text in the articles. The advantage of having access to this wide availability of content is important, because it allows us to employ the LDA method for recovering topic-based measures for many different types of uncertainty such as macroeconomic, financial and political as well as monetary policy and fiscal policy. As a small open economy, we find it to be important to also expand our set of measures to capture foreign uncertainty that is discussed in the local newspapers as

\footnotetext{
3 The LDA algorithm involves two main steps. First, for each newspaper article, the process starts by randomly choosing a distribution over topics. In the second step, each word in each document is then drawn from one of the topics, where the selected topic is chosen from the per-document distribution over all topics. In this way, all documents will always share the same number of topics but with different proportions. Readers are referred to Blei (2012) for more details on the algorithm.

4 These are (i) Bangkok Biz News, (ii) Daily News, (iii) Matichon and (iv) Thairath.
} 
well, especially on topics related to the US and China which are Thailand's important trading partners.

A key consideration when using the topic modeling approach is that the number of topics need to be set exogenously. There is no set rule for this choice as it depends on the nature of the corpus. We end up estimating a 50-topic model, where full details of the LDA approach proposed by Azqueta-Gavaldon (2017) as well as how we evaluate the number of topics based on both goodness-of-fit evaluation and on interpretability criteria are summarized in Appendix B. Based on our 50-topic model, we then tag each individual topic by carefully inspecting the word clouds. ${ }^{5}$ Since these tags cover a variety of topics, we select only those topics that fall into the following five categories, which are categories of uncertainty that we deem highly important to the Thai economy. These are: (i) global economic uncertainty, (ii) Thai macroeconomic uncertainty (with subcategories on growth outlook and on prices of commodities and agricultural products); (iii) Thai financial uncertainty (with subcategories on capital market and credit markets); (iv) Thai political uncertainty (no subcategories); and (v) Thai economic policy uncertainty (with subcategories on monetary policy and fiscal policy).

The most frequent words that appear in the word clouds for each subcategory are listed in Table 1. As shown, global uncertainty has to do mainly with issues pertaining to the US and China, and given that Thailand is a small open economy, it is not surprising to see that there is also a heavy emphasis on trade uncertainty. We also find that each type of domestic uncertainty is described clearly by the most frequently appeared words. Next, to get a sense of how important each of our five selected topics are, Fig. 2 plots the proportion of newspaper coverage for each of the five topics over the 2017Q1-2019Q4 sample. ${ }^{6}$ As shown, while there exists some variation in the coverage of each topic, the share belonging to each topic remains relatively constant over time since there is no upward or downward trend. We find that the largest share of uncertainty-related topic belongs to domestic macroeconomic uncertainty $(36 \%$ on average), followed by global economic uncertainty $(27 \%)$, domestic economic policy uncertainty (19\%), financial uncertainty (15\%) and last, political uncertainty (3\%). Interestingly, the top three topics already account for over $80 \%$ of economic uncertainty-related news in Thailand.

Investigating further at the subcategory level, we find that uncertainty-related topics that pertain to prices of oil and agricultural products as well as Thai growth outlook on exports receive the top shares in domestic macroeconomic uncertainty. For global uncertainty, most topics are unsurprisingly related to the macroeconomic performance and economic policies of the US and China. In the estimated financial uncertainty measure, news on credit market uncertainty (e.g. on bank lending) dominate those that are related to capital (mostly equity) markets. Finally, we find that among policy

\footnotetext{
5 They are in Thai language and are available upon request.

6 Note that although there are more than five topics in the full corpus, since we choose to discard the remaining topics that cover other uncertainty-related issues such as those on education, the environment, healthcare and housing, we scale the total count of uncertainty-related articles in our five selected topics to 100. In this way, we can focus on analyzing how important each of these five topics are in relation to each other. This is also for visual purposes of viewing Fig. 2, since the number of other uncertainty-related topics that we discard are quite large.
} 


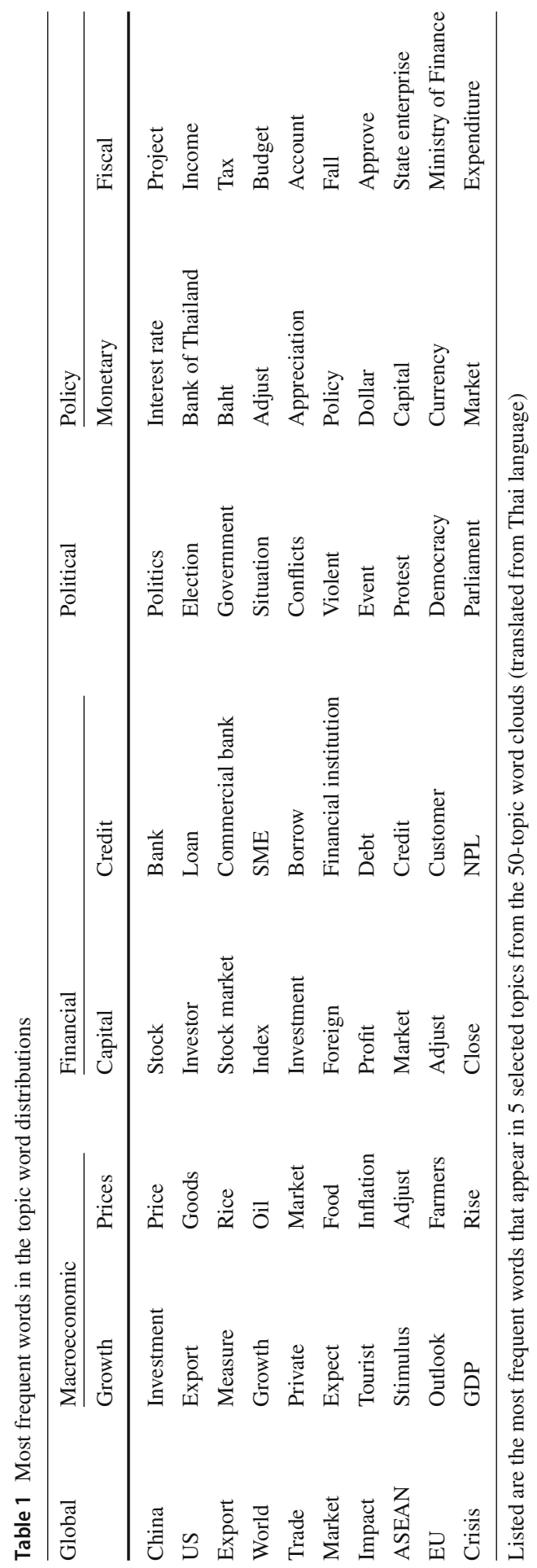




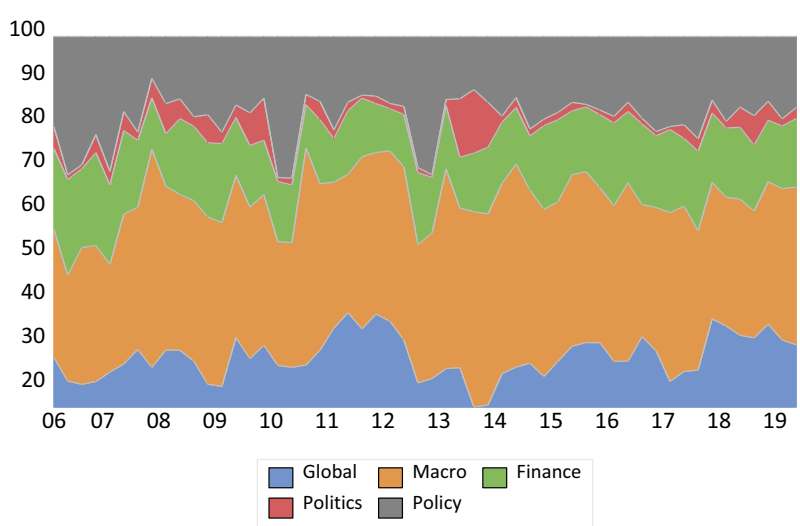

Fig. 2 Estimated topic proportions of news-based uncertainties in Thailand. Note Topic proportions are calculated as the percentage share of how frequent a particular topic appears in the full set of uncertaintyrelated news. The full count of uncertainty-related news for the five topics are scaled to 100

uncertainty measures, monetary policy uncertainty receives a larger proportion of newspaper coverage than fiscal policy uncertainty. Most topics are related to issues of the Thai exchange rate which is not surprising given that Thailand is a small open economy and the Thai policy interest rate has been unchanged for more than three years during June 2015-November 2018.

Figure 3 plots the evolution of our five news-based uncertainty indicators along with their subcomponents (all in standardized scales) against other measures of the same type that are available in the literature. For global uncertainty this is the GEPU measure constructed using the BBD approach by Davis (2016) and for Thai political uncertainty this is the news-based political uncertainty index as constructed by Luangaram and Sethapramote (2020) via a Boolean search of key political terms such as those that denote conflict in Thai local newspapers. For comparison purposes, we also plot our model-based macroeconomic and financial uncertainty indices. Some interesting observations are as follows. First, in Panel (a), we find the largest spike in our LDA global uncertainty indicator to occur during the GFC, while GEPU has been on a rising trend since 2007. Thus, while both share some co-movements, their correlation is only $16 \%$, which reflects that there are many dimensions to global economic policy uncertainty. Second, our model-based macroeconomic uncertainty measure in Panel (b) is more consistent with news-based uncertainty on prices of commodities and agricultural products (67\% correlation) rather than growth outlook ( $26 \%$ correlation). Given that the JLN model-based measure is constructed from a large set of economic and financial time series, it is by nature broad-based. Accordingly, this casual observation seems to suggest that uncertainty about the Thai macroeconomy as a whole is mostly driven by uncertainty about prices of commodities rather than uncertainty on economic outlook.

Next, according to Panel (c), we find that as expected, uncertainty in capital markets is rather volatile. Furthermore, we find that the broad-based JLN measure of financial uncertainty is more closely aligned with credit market uncertainty, which is consistent with the fact that the Thai financial system is heavily bank-based. In Panel (d), we 


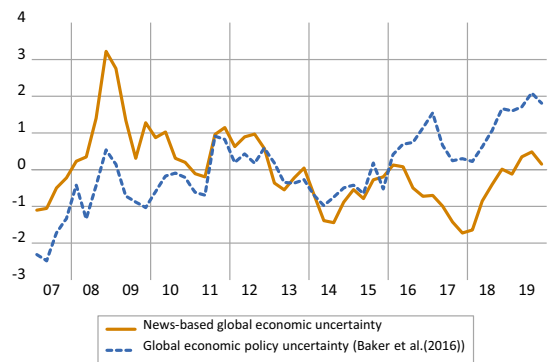

(a) Global Economic Uncertainty
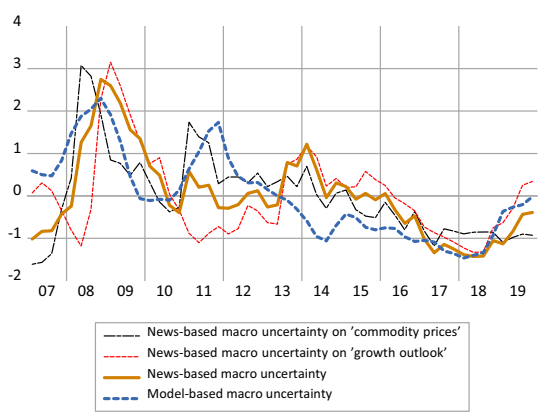

(b) Macroeconomic Uncertainty

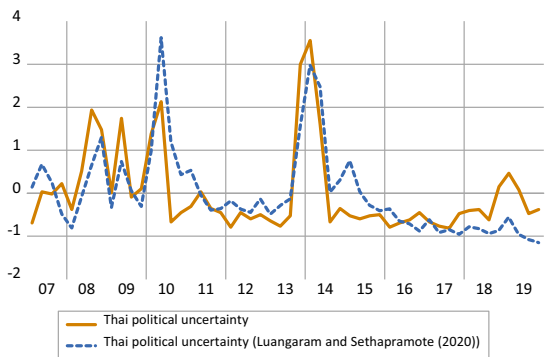

(d) Political Uncertainty

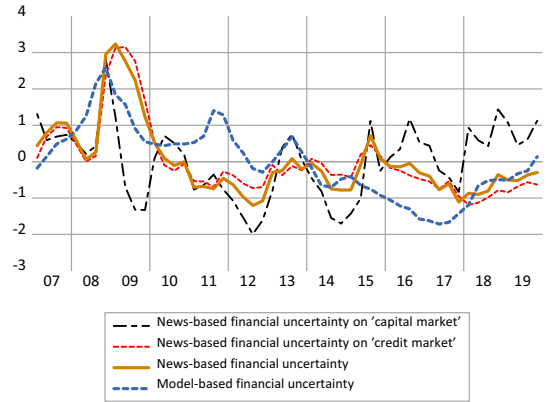

(c) Financial Uncertainty

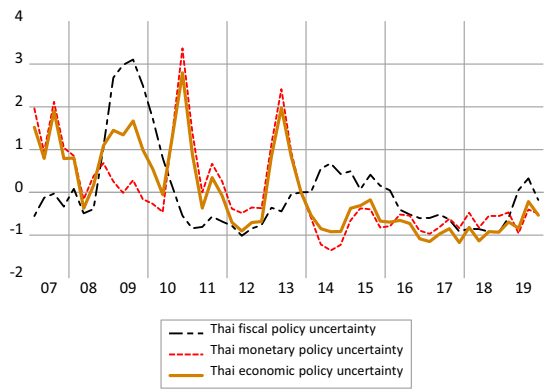

(e) Economic Policy Uncertainty

Fig. 3 News- and model-based uncertainty indicators. a Global economic uncertainty. b Macroeconomic uncertainty. c Financial uncertainty. d Political uncertainty. e Economic policy uncertainty. Note Plotted are our news and model-based uncertainty indicators based on LDA and JLN approaches. Panels a and d also contain uncertainty indicators that are borrowed from the literature which include the news-based global economic policy index (Baker et al. 2016) and the Thai political uncertainty index (Luangaram and Sethapramote 2020) that are constructed from Boolean search methods

find that political uncertainty as constructed by the unsupervised LDA approach and the BBD Boolean search method of Luangaram and Sethapramote (2020) exhibit a very strong correlation of $76 \%$. They also both capture the key episodes of political crises in Thailand during the 2007-2014 period extremely well, which is a period of unprecedented political violence and deep polarization across the whole nation that consumed 7 prime ministers and 2 military coups (in 2006 and 2014). Finally, 
Table 2 Description of uncertainty measures

\begin{tabular}{ll}
\hline Type & Description \\
\hline 1. Global & First principal component of our news-based global uncertainty, the Global \\
& Economic Policy Uncertainty Index Baker et al. 2016, US \\
& macroeconomic uncertainty (Jurardo et al. 2015), US financial \\
& uncertainty (Ludvigson et al. forthcoming) \\
First principal component of our news-based macroeconomic uncertainty & and our JLN model-based macroeconomic uncertainty. Subcomponents \\
of the news-based measure include (i) production and economic growth \\
and (ii) prices of commodities and agricultural products \\
First principal component of our news-based financial uncertainty and our \\
JLN model-based financial uncertainty. News-based subcategories \\
include: (i) capital markets and (ii) credit markets \\
First principal component of our news-based political uncertainty and the \\
Luangaram and Sethapramote (2020) Thai political uncertainty index. \\
No subcategories \\
Our news-based economic policy uncertainty with subcategories including \\
(i) monetary policy uncertainty, (ii) fiscal policy uncertainty (no PCA \\
applied)
\end{tabular}

Panel (e) displays movements in monetary policy and fiscal policy uncertainty. We observe that fiscal policy uncertainty contains a highly distinct large spike in 2008 which captures the concerns over the delay of fiscal stimulus in response to the GFC. As for monetary policy uncertainty, we find two major spikes in 2010 and 2013 that are related to tensions of the Thai baht appreciation, which as a result brought about concerns over the direction of monetary policy. Given that overall Thai economic policy uncertainty moves more in tandem with monetary policy uncertainty, we again can conclude that policy uncertainty in the news media is more focused on monetary policy related issues.

\subsection{Principal component uncertainty}

So far, we have introduced a number of uncertainty measures that are important to Thailand. These include measures that we construct on our own as well as indicators that we borrow from the literature. Since a few measures belong to the same category, we apply the principal component analysis (PCA) to uncertainty measures that are of the same type but differ by method of construction to obtain a single measure that represents uncertainty along each of the five dimensions, so that we can later investigate its dynamic impact on key macro and financial variables in Thailand. ${ }^{7} \mathrm{~A}$ summary of these PCA-based measures is given in Table 2.

Our motivation for applying the PCA method is that we realize that there is no single perfect indicator of uncertainty. This is reflected by the numerous proxies for

\footnotetext{
${ }^{7}$ In the literature, the PCA has often been employed to gauge the overall level of uncertainty across a swathe of uncertainty proxies that are often available, and has been shown to capture the common movements among the various indicators of uncertainty well (see Haddow et al. 2013; Forbes 2016 and Redl 2017, among others).
} 
global uncertainty that have been proposed in the literature, including news-based GEPU, JLN US uncertainty, BBD news-based US uncertainty, the VIX index and many more. Therefore, to capture global uncertainty, it would be best to take the common movement across available measures as its proxy. Thus, we applied the PCA to a group of popular measures and found the first principal component of the GEPU, JLN US macroeconomic and financial uncertainty and our LDA global uncertainty measure to be a robust indicator. ${ }^{8}$ Note that while most global uncertainty indicators that we select move more or less in the same direction (average correlation is 0.37 ), the correlation values range from -0.21 (JLN US macroeconomic uncertainty and GEPU) to 0.81 (our LDA measure and JLN US financial uncertainty). For the remaining domestic uncertainty measures, the correlation values are much higher. For macroeconomic and financial uncertainty, the correlation between the model-based and LDA pair is 0.61 and 0.58 , respectively, while the correlation between our LDA measure and the Luangaram and Sethapramote (2020) political uncertainty index is 0.76 .

Figure 4 contains plots of our PCA-based global and domestic uncertainty indicators. Upon first glance, PCA-based macroeconomic and financial uncertainty indicators look surprisingly similar to global uncertainty. They exhibit one large spike during the GFC and has been on a declining trend since then, until the recent rise again at the beginning of 2018. This observation is consistent with their high correlation values of around 0.80 (see Table 3) and reflects that as a small open economy, Thailand receives high degrees of spillover from abroad to macroeconomic and financial realms. For political and economic policy uncertainty, their correlations with global and other types of domestic uncertainty are much lower. An exception is the relatively high correlation between financial and economic policy uncertainty, signifying that policy measures in Thailand may be responding to a significant degree to developments in financial markets. Finally, we find political and economic policy uncertainty to be more volatile than the PCA-based global, macro and financial uncertainty measures. While this could reflect its nature that typically contains more highs and lows, this result could be measurement dependent since political and policy uncertainty measures are based solely on news-based indicators, which are known to be noisier than model-based ones.

\section{Data and empirical setup}

Our goal in this section is to examine the responses of key macro and financial variables to global and domestic uncertainty innovations, which for purposes of brevity we will often refer to as global and domestic "shocks." In doing so, we follow the standard approach in the literature and estimate a structural VAR, where a common representation is:

$$
B_{0} y_{t}=B(L) y_{t-p}+\epsilon_{t} .
$$

\footnotetext{
8 That is, our empirical results are robust to other global uncertainty measures that includes applying the PCA to combinations of the BBD US news-based uncertainty, the Euro area news-based uncertainty and the VIX index as well.
} 
Global economic uncertainty

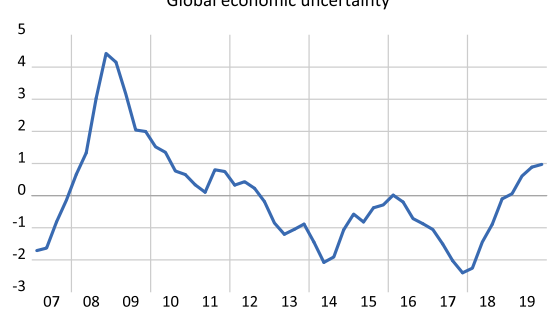

(a) Global Economic Uncertainty

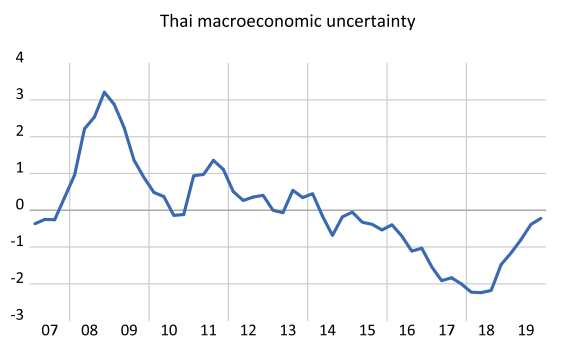

(b) Macroeconomic Uncertainty

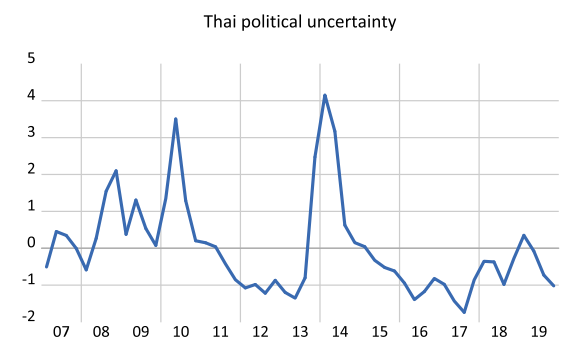

(d) Political Uncertainty

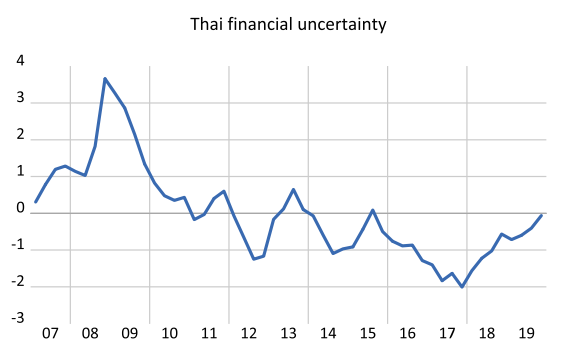

(c) Financial Uncertainty

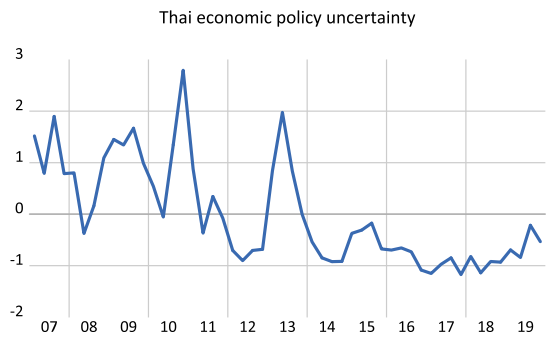

(e) Economic Policy Uncertainty

Fig. 4 Principal component measures of uncertainty. a Global economic uncertainty. b Macroeconomic uncertainty. c Financial uncertainty. d Political uncertainty. e Economic policy uncertainty. Note PCAbased measures of uncertainty are constructed by taking the first principal component of news-based and model-based uncertainty measures (details as outlined in Table 2)

In the above specification, $y_{t}$ is a vector of endogenous variables, representing the global and local economy, $B(L)$ is an autoregressive lag-polynomia, and $\epsilon_{t}$ is the vector of structural innovations. We recover the structural shocks $\epsilon_{t}$, which contains the global and local uncertainty shocks of interest from $\epsilon_{t}=B_{0} u_{t}$, where $B_{0}$ contains the contemporaneous relationships between the reduced-form residuals $u_{t}$ and the structural shocks $\epsilon_{t}$. To identify $B_{0}$, we employ a standard Cholesky decomposition which imposes a lower triangular matrix.

To identify the effects of global and local uncertainty shocks via a Cholesky decomposition, the ordering of the variables in $y_{t}$ is important. As a starting point, we consider a similar ordering to the domestic VAR of Baker et al. (2016) where the uncertainty 
Table 3 Correlation among PCA-based uncertainty measures

\begin{tabular}{llllll}
\hline & Global & Macro & Financial & Political & Policy \\
\hline Global & 1 & & & & \\
Macro & 0.79 & 1 & & & \\
Financial & 0.79 & 0.85 & 1 & & \\
Political & 0.26 & 0.40 & 0.43 & 1 & \\
Policy & 0.42 & 0.52 & 0.73 & 0.19 & 1 \\
\hline
\end{tabular}

measure is ordered first. ${ }^{9}$ Then we extend the VAR to include small open economy variables such as the exchange rate and a capital flow measure. Similar in spirit to Favero and Giavazzi (2008) and Colombo (2013), we also include a set of core global variables, constituting a global block which enters before the domestic block in the VAR, while placing zero restrictions on the global block to ensure that shocks hitting the domestic economy exerts no contemporaneous effects on the global variables. This is based on the idea that since Thailand is a small open economy, the transmission of global uncertainty shocks is likely to be unidirectional, and the global shock identified in this way should be truly exogenous.

The resulting 11-variable SVAR contains variables in $y_{t}$ of the following order:

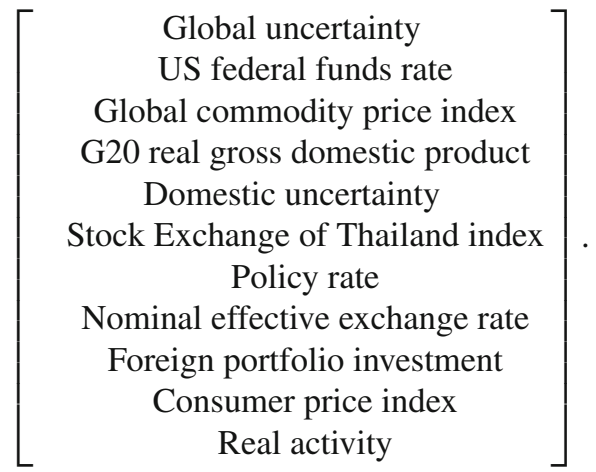

where our focus is on analyzing the impact of global and domestic uncertainty shocks on key financial and real activity variables. Financial variables that we focus on include the stock exchange of Thailand index (SET), nominal effective exchange rate (NEER) and foreign portfolio investment (FPI) while key real activity variables include real gross domestic product (RGDP), consumption (C), investment (I), exports (X) and imports (IM), which are entered one at a time as the last variable in the VAR. In

\footnotetext{
9 Another popular ordering of the VAR in the literature is one of the reverse orders with uncertainty ordered last. We performed the reverse-order analysis as a robustness check, where the interpretation of our findings did not change significantly. Nevertheless, it is still unclear whether uncertainty should be placed before or after the real activity variable. Also, there is a recent strand of the literature that debates whether the recursive VAR identification approach is a relevant approach at all, given that there may be reverse caUSlity between uncertainty and real activity. Few studies that address this potential endogeneity of uncertainty propose novel identification procedures (Carriero et al. 2018b; Cesa-Bianchi et al. 2018; Mumtaz 2018; Angelini et al. 2019; Ludvigson et al. forthcoming), but so far have delivered empirical results that are quite mixed.
} 
the above VAR, all variables are in log levels and deseasonalized except for interest rates, which are in levels. ${ }^{10}$ Following Baker et al (2009) and Azzimonti (2019), we analyze FPI as the net FPI flow scaled by its cumulative FPI position at the end of quarter t-1 and transform it according to $\left.\ln (y)=\ln \left(x+\sqrt{(} x^{2}+1\right)\right)$ as in Busse and Hefeker (2007) to deal with some observations that are negative. Finally, in the VAR specification, we include a constant and one lag for all variables based on information criteria tests. $^{11}$

In the empirical analysis, we estimate the baseline VAR described above repeatedly by keeping the global block constant, but alternating between different types of domestic uncertainty measures (including their subcomponents) as listed as items 2-5 in Table 2, as well as domestic real activity variables (RGDP, C, I, X and IM). Our data are quarterly and spans 2007Q1-2019Q4 where the beginning marks the first date in which our constructed news-based uncertainty measures are available and the end sample date is chosen to avoid possible nonlinearities due to rising uncertainty during the COVID-19 crisis. Data sources are from the Federal Reserve Bank (FRED) (US federal funds rate), OECD database (G20 RGDP), IMF database (global commodity prices) and Bank of Thailand database (Thai macro and financial variables). Global uncertainty measures that we borrow from the literature can be downloaded from http:// www.policyuncertainty.com (GEPU) and http://sydneyludvigson.com (US macroeconomic and financial uncertainty). The Thai political uncertainty index is requested from the authors (Luangaram and Sethapramote 2020). Finally, for estimation of the VAR, we employ maximum likelihood methods and compute impulse response functions and forecast error variance decompositions. Due to the small sample of our dataset, in our impulse response function analysis, we correct for any potential bias in the bootstrapped confidence intervals by employing the methods as outlined in Kilian (1998) and Phillips and Spencer (2011).

\section{Empirical results}

In this section, we investigate the response of our core set of real activity and financial variables to both global and domestic uncertainty shocks. ${ }^{12}$ The real activity responses to uncertainty are reported in Figs. 5, 6, 7 and 8 with each row representing the dynamic impact of global and domestic shock innovations on RGDP, C, I, X and IM, which enter one at a time as the last variable in separate empirical VARs. For financial variable responses shown in Figs. 9, 10, 11 and 12, all dynamic responses for the SET, NEER and FPI are obtained from estimating a single empirical VAR with RGDP as

\footnotetext{
10 The majority of VARs in the literature that investigate the effects of uncertainty are in levels except for some that consider growth or HP-filtered variables. According to Sims et al. (1990), VARs in log levels provide consistent estimates of the IRFs even in the presence of co-integrating vectors.

11 Information criterion tests suggest either VARs with 1 or 2 lags, so we select a VAR with 1 lag due to the large number of endogenous variables in the VAR. The results are also robust to VARs with 2 lags. To ensure no model misspecification, we also perform multivariate Portmanteau tests to ensure no serial correlation in the error terms of the VAR models.

12 We also obtain the impulse responses of inflation and the policy rate to global and local shocks but we do not wish to discuss them here since the Thai CPI and policy rates have been relatively stable throughout the sample under investigation.
} 

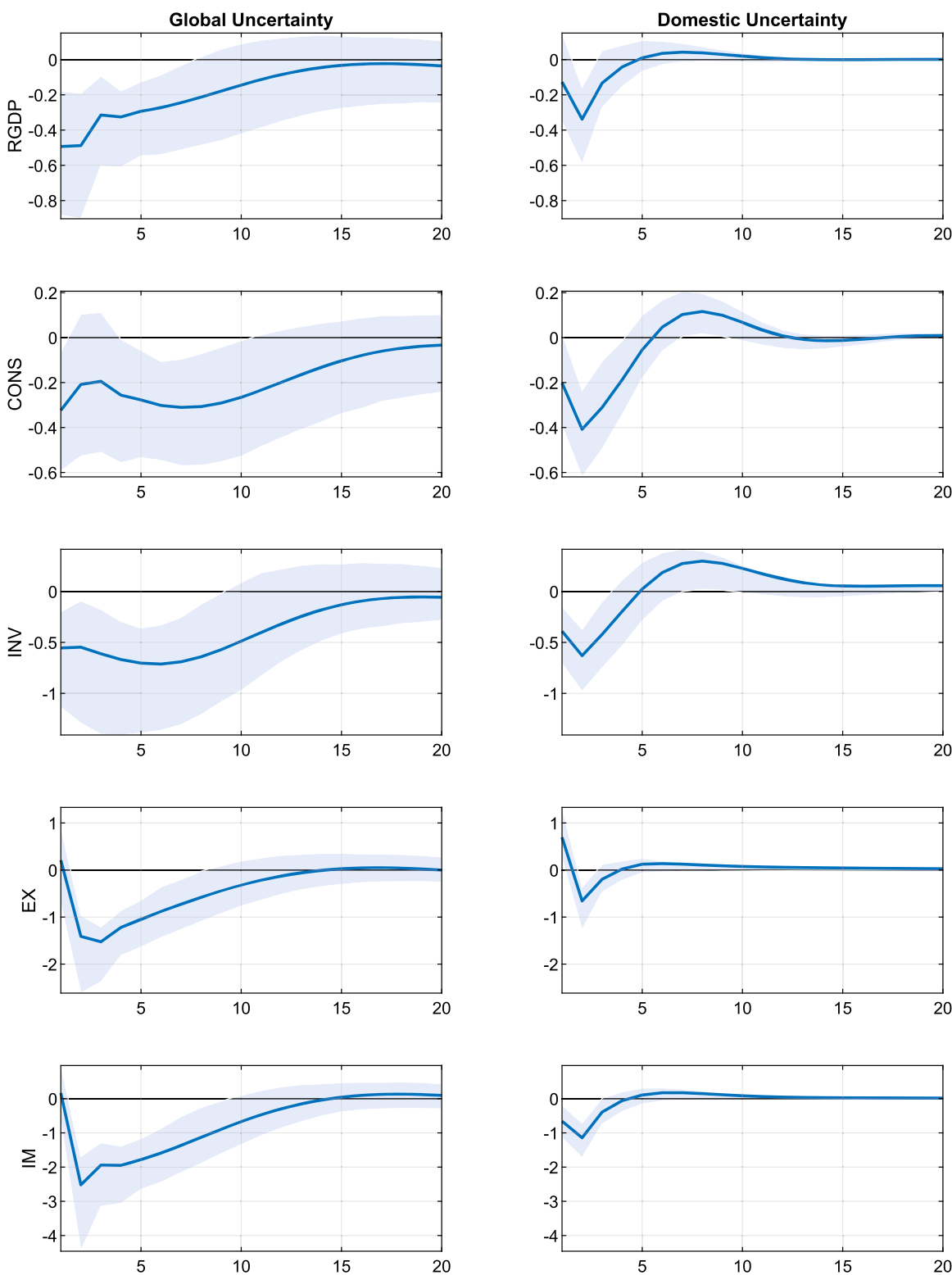

$.68 \mathrm{Cl} \longrightarrow$ Point Estimate

Fig. 5 Impulse responses of real activity variables to global uncertainty and domestic macroeconomic uncertainty shocks. Note Plotted are the impulse responses to global and domestic macroeconomic uncertainty shocks. Shaded regions correspond to $68 \%$ standard error bands 

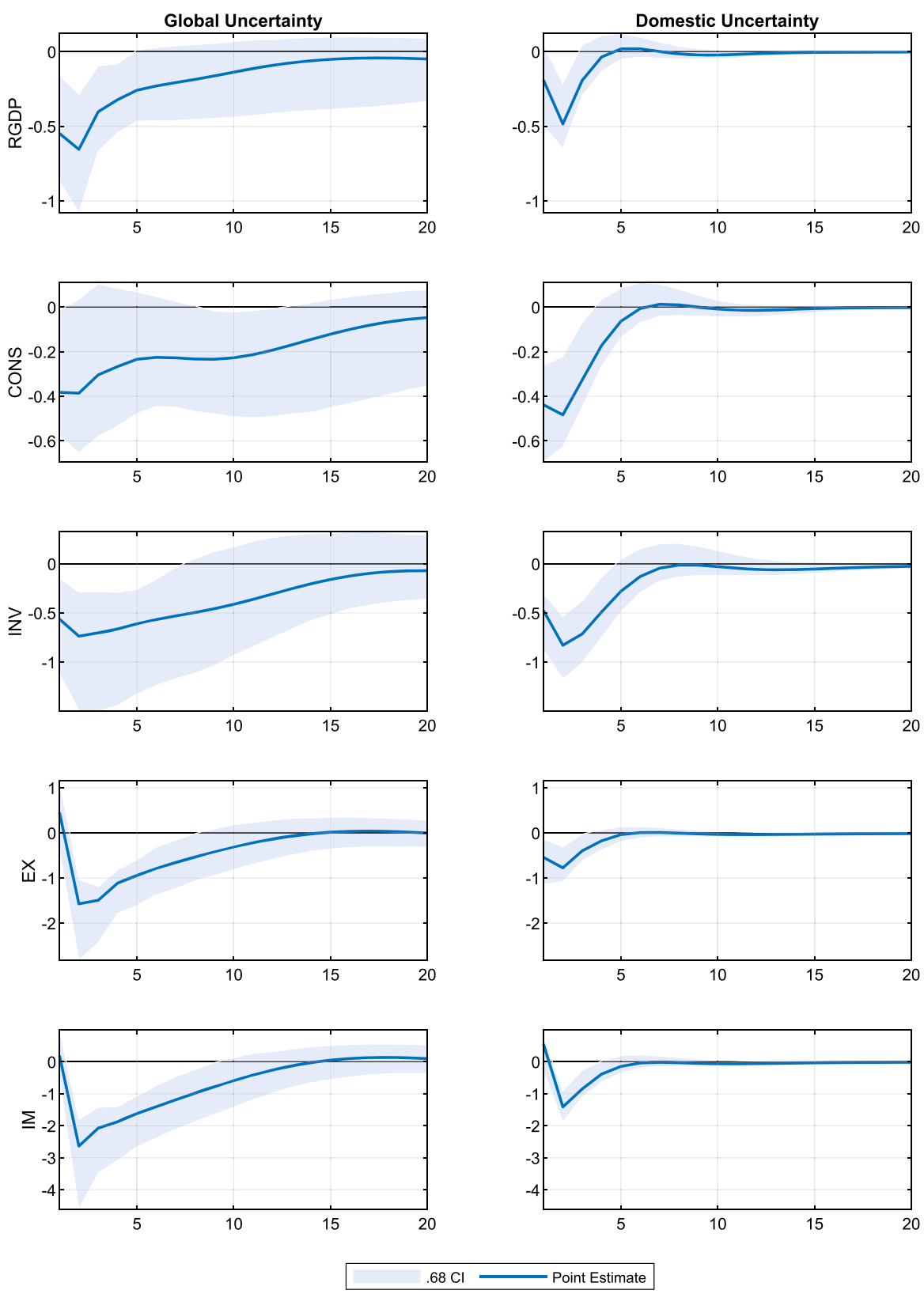

Fig. 6 Impulse responses of real activity variables to global uncertainty and domestic financial uncertainty shocks. Note Plotted are the impulse responses to global uncertainty and domestic financial uncertainty shocks. Shaded regions correspond to $68 \%$ standard error bands 

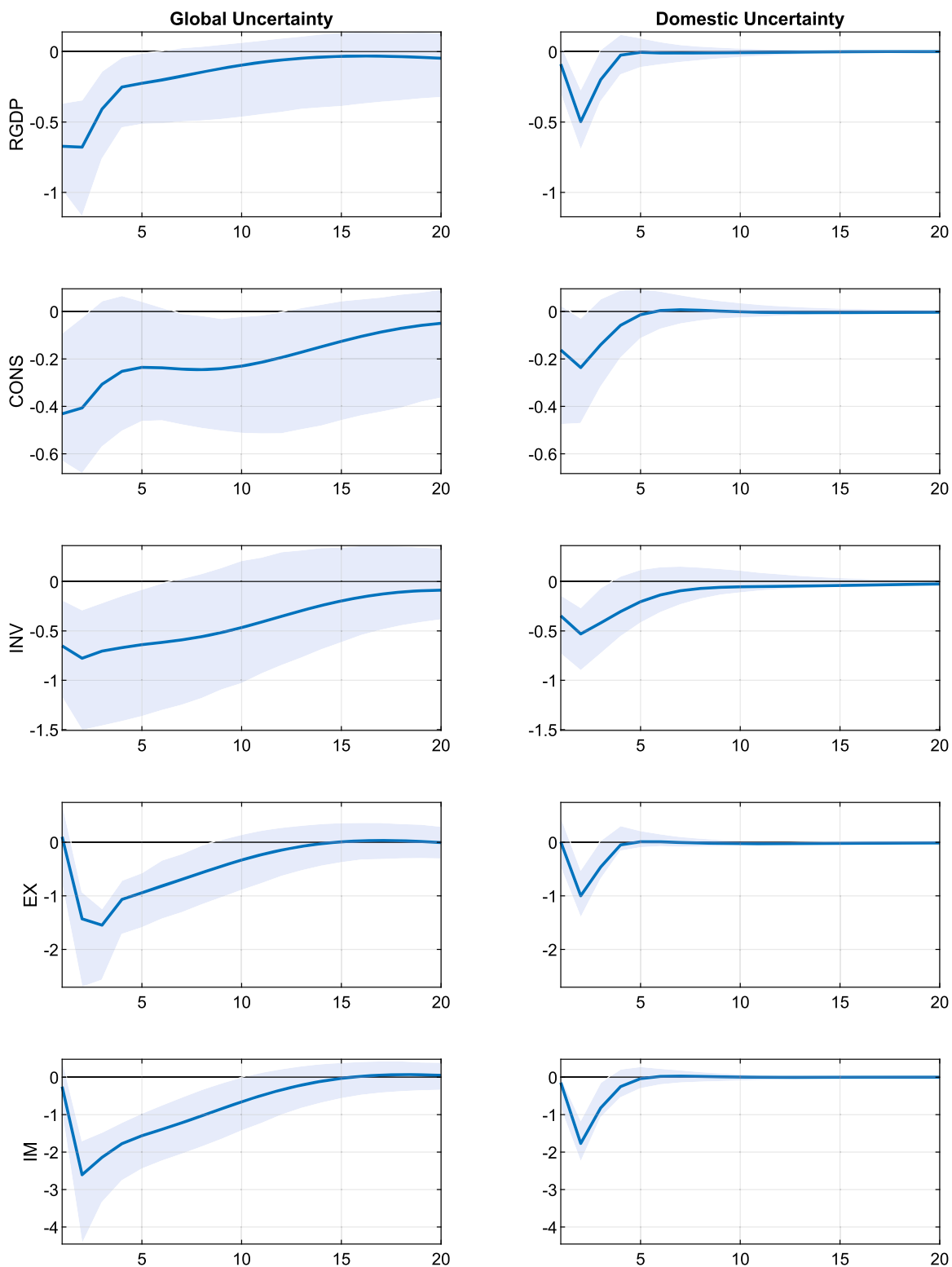

$.68 \mathrm{Cl}$

Point Estimate

Fig. 7 Impulse responses of real activity variables to global uncertainty and domestic political uncertainty shocks. Note Plotted are the impulse responses to global uncertainty and domestic political uncertainty shocks. Shaded regions correspond to $68 \%$ standard error bands 

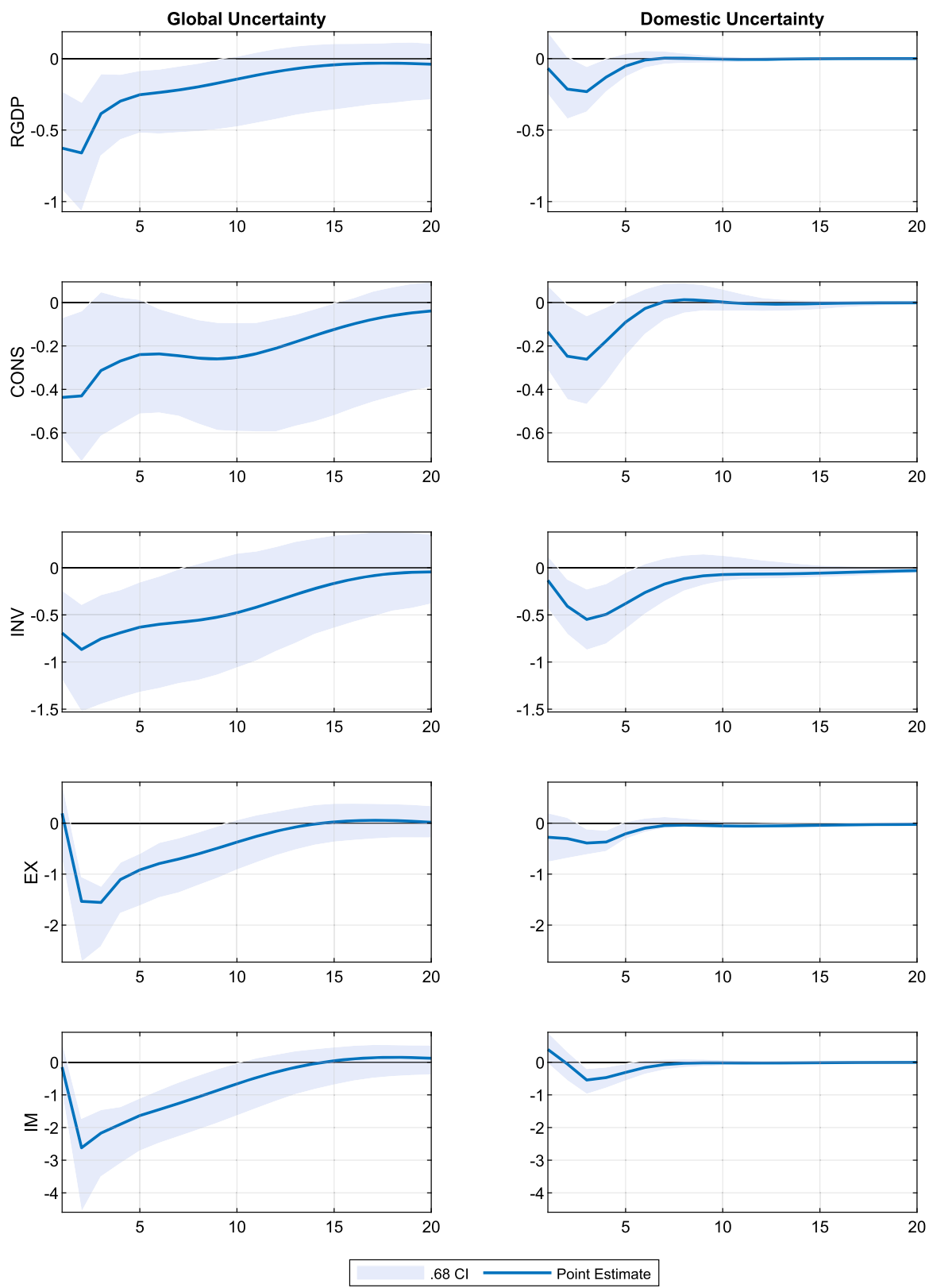

Fig. 8 Impulse responses of real activity variables to global uncertainty and domestic economic policy uncertainty shocks. Note Plotted are the impulse responses to global uncertainty and domestic economic policy uncertainty shocks. Shaded regions correspond to $68 \%$ standard error bands 

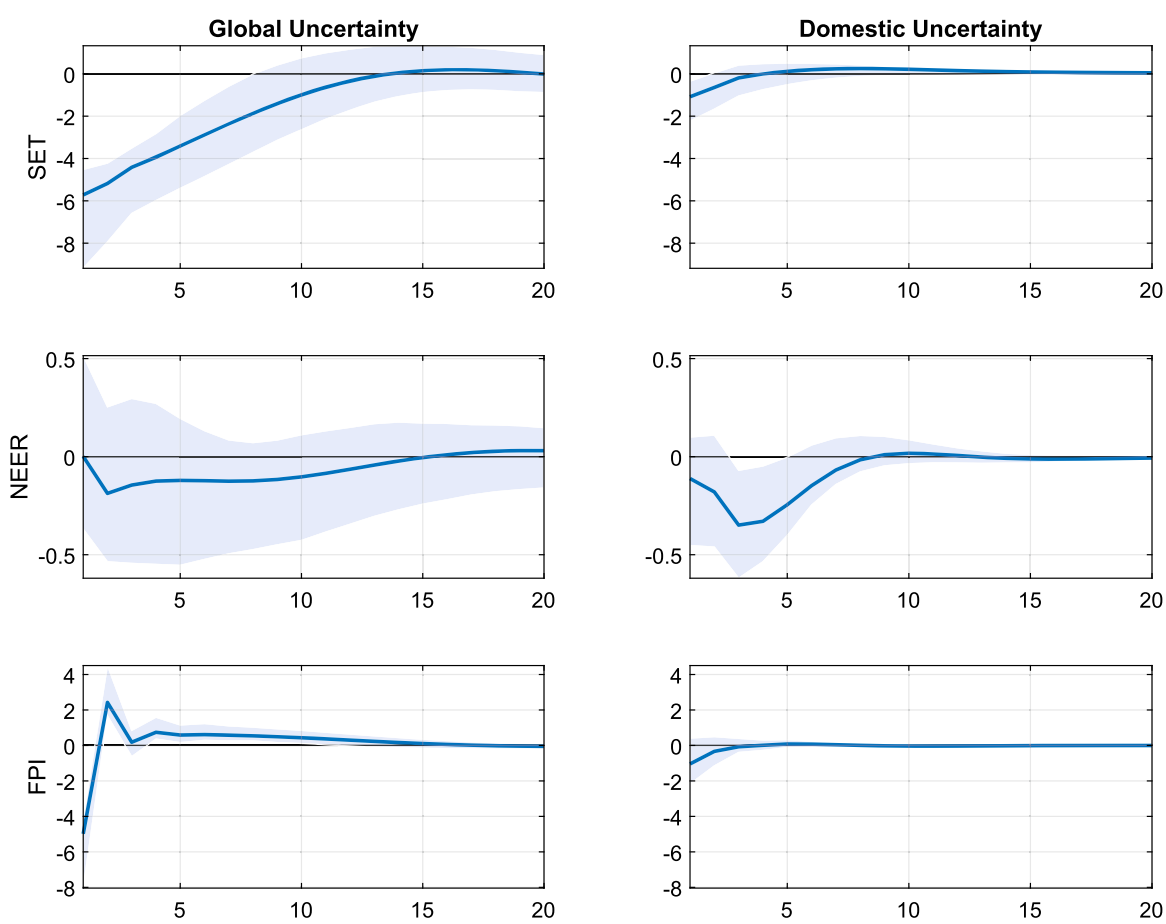

$.68 \mathrm{Cl}=$ Point Estimate

Fig. 9 Impulse responses of financial variables to global uncertainty and domestic macroeconomic uncertainty shocks. Note Plotted are the impulse responses to global and domestic macroeconomic uncertainty shocks. Shaded regions correspond to $68 \%$ standard error bands

the real activity variable. Across all figures, the impact of global shock innovations is plotted on the left-hand side column and can be directly compared to its domestic counterpart along the right-hand side column. We then discuss any heterogeneity among uncertainty shocks of different types and report the forecast error variance decomposition results.

\subsection{The impact of uncertainty on real activity}

We first focus on analyzing the real activity impact of uncertainty shocks. According to Figs. 5, 6, 7 and 8, all uncertainty shocks are contractionary and statistically significant. For global shocks, its impact on RGDP is around $-0.6 \%$, with muted effects on consumption $(-0.4 \%)$ but slightly larger effects on investment $(-0.8 \%)$, exports $(-1.5 \%)$ and imports $(-2.5 \%)$. Turning to examine the effect of domestic shocks on real activity, we observe that overall, the effect on RGDP, C and I is only slightly smaller when compared to its global counterpart while its effect is drastically reduced for X and IM. More specifically, peak impacts of one standard deviation domestic uncertainty shocks approximately reduces RGDP by $-0.4 \%$, with the smallest effect 

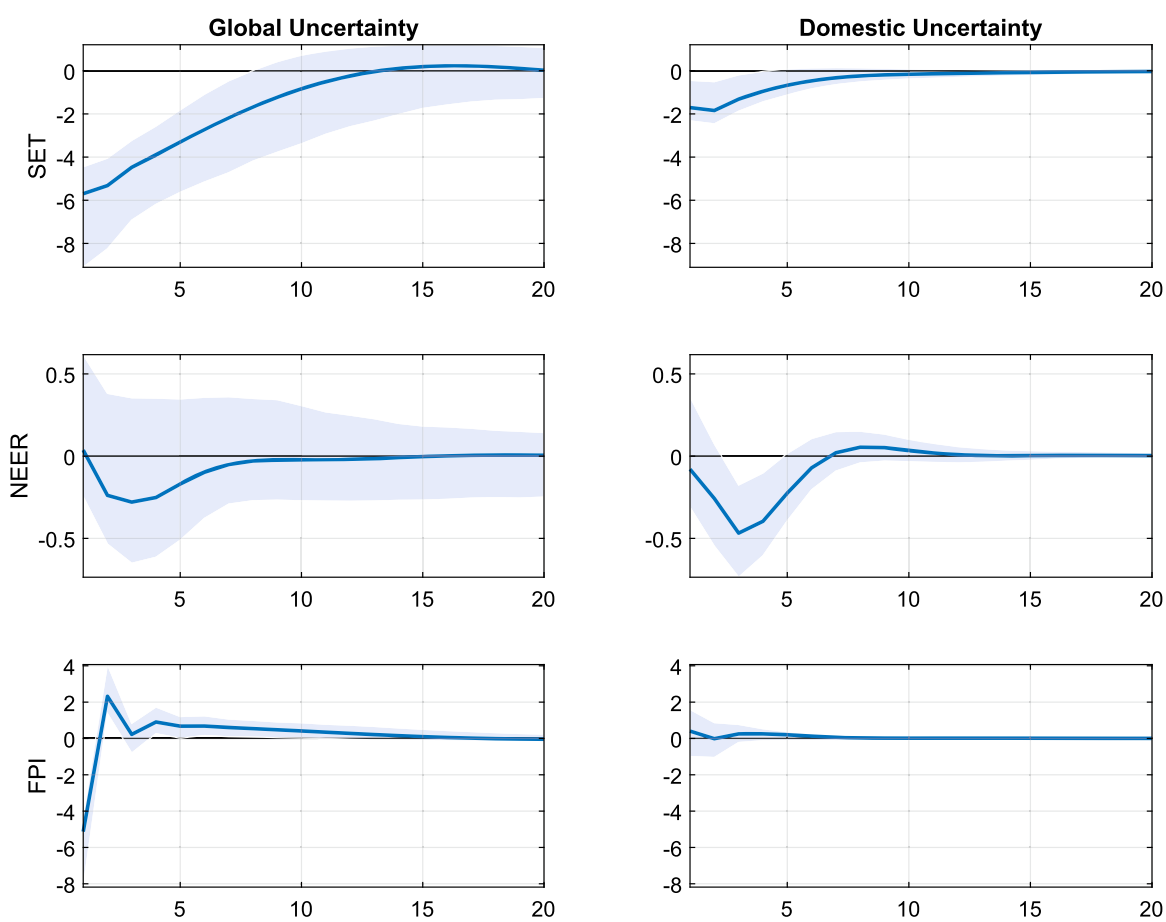

$.68 \mathrm{Cl} \longrightarrow$ Point Estimate

Fig. 10 Impulse responses of financial variables to global uncertainty and domestic financial uncertainty shocks. Note Plotted are the impulse responses to global uncertainty and domestic financial uncertainty shocks. Shaded regions correspond to $68 \%$ standard error bands

through consumption $(-0.3 \%)$, followed by investment $(-0.5 \%)$, exports $(-0.7 \%)$ and imports $(-1.5 \%)$. Finally, in all cases, there are no overshooting effects in contrast to evidences presented by Bloom (2009) for the US and Gourio et al. (2013) for G7 countries, whereby they report that the initial drop in real activity is followed by a swift recovery and subsequent overshoot that surpasses its trend due to firms catching up on hiring decisions that were delayed by uncertainty. ${ }^{13}$

To directly compare the magnitude of Thailand's real activity impact with other countries would be difficult due to differences in sample periods and empirical spec-

\footnotetext{
13 There appears to be some minor evidence of overshooting for the impact of macroeconomic uncertainty shocks on consumption and investment (Fig. 5), but is only marginally significant. For studies that find evidence of overshooting, we notice that they tend to use volatile implied or realized financial market volatility measures as proxies for uncertainty, whereas studies that use alternative proxies for similar countries find no such effect (Jurardo et al. 2015; Cuaresma et al. 2019). Thus, the rebound effect may depend on the type of uncertainty measure used. Alternatively, it may depend upon cross-country differences or the sample period under investigation. Carrière-Swallow and Cèpedes (2013) offer evidence that real activity tends to occur in the medium run for developed economies, while emerging economies do not display a similar pattern. Caggiano et al. (2014) show that if the sample period includes the GFC where most developed central banks switched to unconventional monetary policy measures in the presence of the effective zero lower bound, the overshoot vanishes.
} 

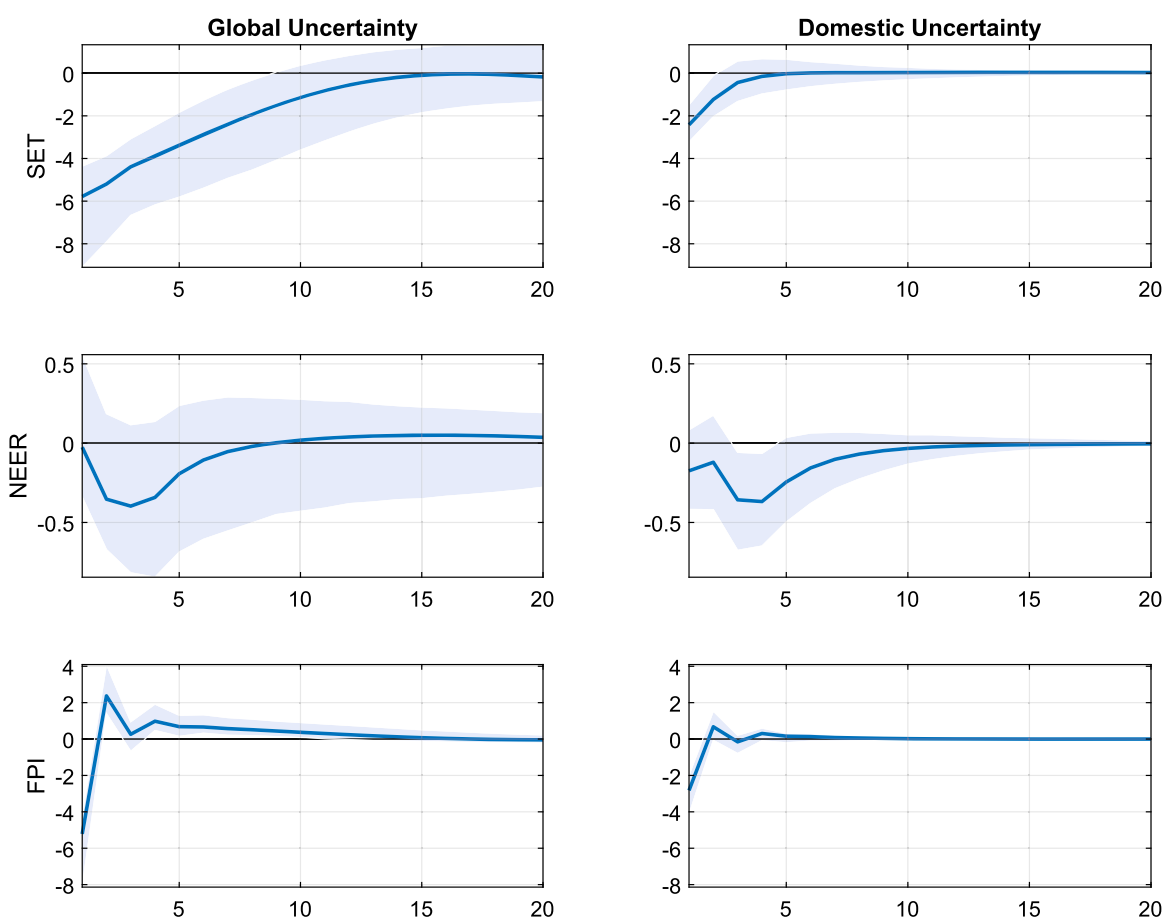

$.68 \mathrm{Cl}=$ Point Estimate

Fig. 11 Impulse responses of real activity variables to global uncertainty and domestic political uncertainty shocks. Note Plotted are the impulse responses to global uncertainty and domestic political uncertainty shocks. Shaded regions correspond to $68 \%$ standard error bands

ifications in place. However, regarding the contraction in real activity following a domestic shock, the estimated size effect for Thailand is more or less in line with those of advanced economies. For example, in the UK, the peak impact of a one standard deviation uncertainty shock on the level of GDP is around $-0.5 \%$ (Haddow et al. 2013). Similarly, for a large number of OECD countries, the impact of domestic uncertainty shocks are less than a percentage point for GDP (Berger et al. 2016). Consistent with our findings, consumption responses in developed nations to uncertainty have also been found to be rather modest (Knotek and Khan 2011; Balta et al. 2013; Berger et al. 2016). Contractions in investment in advanced Euro area countries are also well within the range we observe, which is between -0.5 and $-1 \%$ (e.g., Meinen and Roehe 2017).

Next, we discuss our findings on the effects of global uncertainty on real variables along two dimensions. First, regarding the effect of global shocks on EMEs versus developed nations, our findings contrast Carrière-Swallow and Cèpedes (2013) whom find that emerging market countries suffer a fall in consumption and investment gaps approximately four times as large as found in developed countries. In our paper, the response of RGDP, C and I to a global uncertainty shock is only slightly larger than its domestic counterpart. Therefore, our findings tilt more toward the conclusion reached 

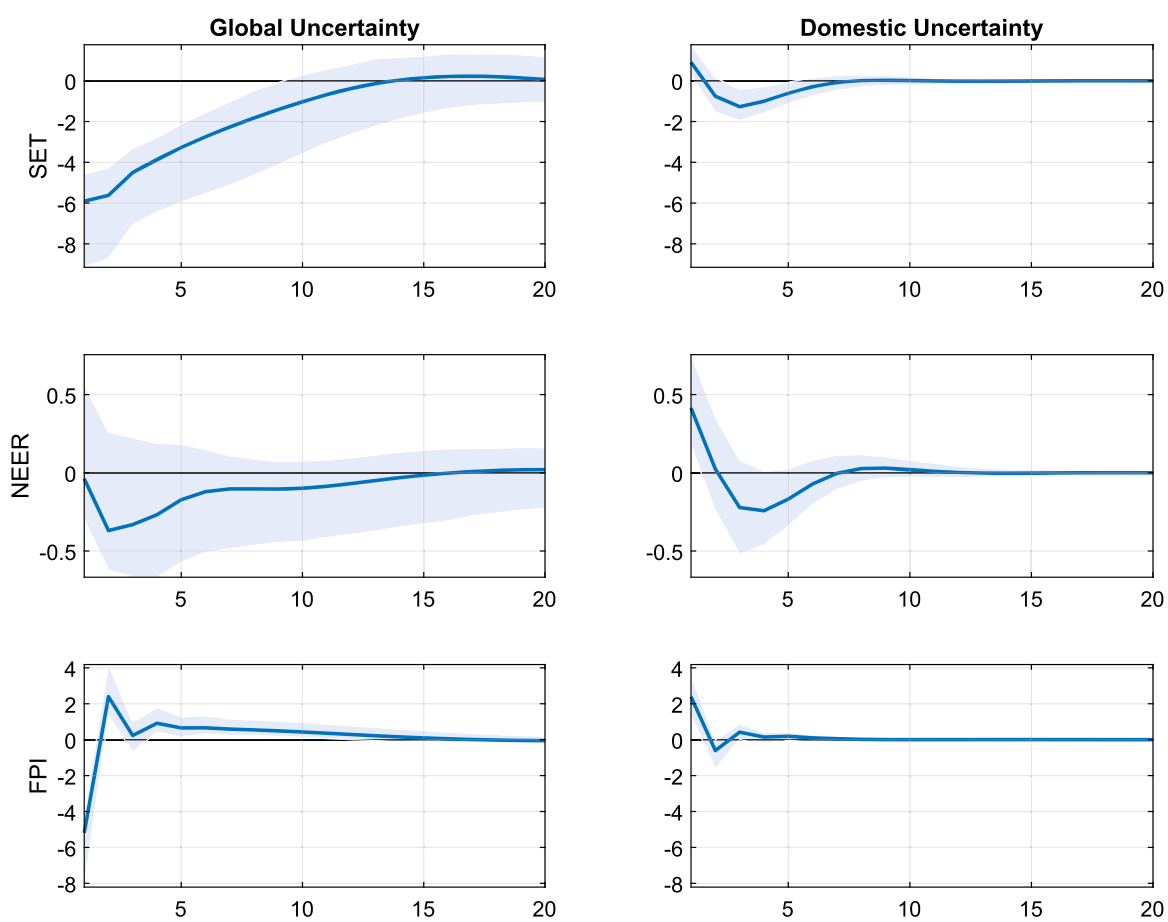

$.68 \mathrm{Cl}=$ Point Estimate

Fig. 12 Impulse responses of financial variables to global uncertainty and domestic economic policy uncertainty shocks. Note Plotted are the impulse responses to global uncertainty and domestic economic policy uncertainty shocks. Shaded regions correspond to $68 \%$ standard error bands

by Bonciani and Ricci (2018) whom do not find significant differences between the response of industrial production to global uncertainty in 36 advanced and emerging small open economies, although some heterogeneity that they do observe across countries are attributed to the country's degree of openness in trade and financial markets. Interestingly, we do find that Thailand's trade variable responses to global uncertainty are larger when compared to those of developed nations that are less reliant on trade. For example, based on the evidence in Cuaresma et al. (2019), global shocks lead to a contraction of only at most $-0.4 \%$ for exports in large $\mathrm{G} 7$ economies.

Second, we compare the size effect of global versus domestic shocks for real activity variables. Our finding that the size of foreign shocks usually dominate within-country ones is consistent with the literature. Based on factor models with stochastic volatility, Mumtaz and Theodoridis (2015) and Berger et al. (2016) decompose time-varying macroeconomic volatility into OECD wide and national macroeconomic uncertainty, in which they find a substantially more important role for the common component. Colombo (2013) and Huang et al. (2018) investigate the spillover of uncertainty from the US to Euro area countries and China, respectively, and find the effect of US uncertainty on national macroeconomic aggregates to be many times larger than its country-own counterpart. Similar to Berger et al. (2016) which investigates the expe- 
riences of 20 OECD countries, we find global uncertainty to be a major driver of macroeconomic performance, especially through investment and trade flows, rather than consumption. In light of these evidences, the importance of global shocks to real activity appears to be a finding that is not only specific to highly open economies.

However, a novel result from our analysis that has not been discussed before in the literature is that there is a stark difference between the persistence of global versus domestic uncertainty shocks. Based on our findings, the effect of domestic shocks for Thailand, irrespective of the type, typically subsides by 5 quarters and, in a few cases, 10 quarters. Global shocks on the other hand, consistently take between 15 and 20 quarters to dissipate. As such, the time that it takes for global versus domestic shocks to subside is a stark difference of approximately 2-3 years. Furthermore, while the effect of all shocks bottom out within about three years, the impact of global shocks are consistently more sudden compared to its domestic counterpart, especially for nontrade variables (RGDP, C and I). Therefore, not only do we find that the economic impacts of global uncertainty shocks for Thailand to be large, their effects are also sudden as well as long-lasting.

\subsection{Impact on financial variables}

We next turn to examine the effect of global and domestic uncertainty shocks on key financial variables, namely the Thai stock market, the nominal exchange rate and FPI. According to Figs. 9, 10, 11 and 12, the impact of uncertainty on financial variables are clearly contractionary, generating sudden and rather substantial impacts. ${ }^{14}$ An exception is the impact of uncertainty on exchange rates which is statistically insignificant in most cases. Also, we find that as before, the impacts of global shocks are larger than domestic ones, which suggests that push factors are key determinants of capital flows and asset price movements in Thailand. This finding is in line with a growing literature which provides evidence of a global financial cycle, in which fluctuations in risky assets and capital flows are mainly driven by global uncertainty and risk factors (Forbes and Warnock 2012; Rey 2013).

One striking result from our analysis is the sudden impact and large magnitude of the contraction in SET and FPI following a global uncertainty shock. More specifically, stock prices and FPI bottom out upon impact, declining to $-6 \%$ and $-5 \%$, respectively. The sudden nature of the response implies that uncertainty swiftly affects the financial market before transmitting to the real economy. As for the size, it is considered to be approximately twice the magnitude of its corresponding effect on trade flows, which was already considered large. This sudden decline in both asset prices and capital flows signals a "flight to safety/quality" phenomenon, whereby during periods of heightened global uncertainty, investors reduce aggregate spending and pulls capital out of an emerging market such as Thailand which may be perceived to be riskier.

While we find a large contraction in FPI in response to global shocks, the effect is short-lived and subsides by within a year. This behavior is consistent with the

\footnotetext{
14 Note, however, that not all types of capital flows may react alike to uncertainty. For example, Hlaing and Kakinaka (2019) shows that for 50 developed and emerging markets, global uncertainty clearly increases the likelihood of contractions in FPI for all countries, while it increases FDI in only advanced economies
} 
easily reversible nature of FPI flows (Razin et al. 1998). However, the effect of global uncertainty shocks on Thai stock markets are rather persistent, lasting for almost 15 quarters. Comparing our results to the literature, Bhattarai et al. (2020) also find a decline in local stock markets and a decrease of capital inflows into EMEs following an increase in US uncertainty, although their average estimated magnitude across EMEs was smaller at $-2 \%$ for stock prices and $-0.5 \%$ for capital flows. Similar to us, however, they also find the impact of foreign shocks on local stock markets to be rather long-lasting, on par with the level of persistence for real activity variables. Nevertheless, our finding of a sizable and persistent impact of uncertainty on stock prices is not alarming. In fact, even in response to a domestic uncertainty shock, Miescu (2019) finds that the average stock decline in fifteen small emerging EMEs to be as large as $-7 \%$, in contrast to only a $-1 \%$ decline in GDP.

Finally, we are reluctant to confirm any tight connection between uncertainty and exchange rates given that the impact of uncertainty shocks on the exchange rate are statistically insignificant for global shocks. Furthermore, while we find that a domestic shock leads to a depreciation of the nominal exchange rate, its magnitude is rather small (less than half a percentage point) and is only marginally significant in some cases. Theoretically, it is unclear whether uncertainty should appreciate or depreciate the exchange rate. For example, Benigno et al. (2012) shows that how uncertainty affects exchange rates depends on whether the currency is relatively considered safe and a good hedge instrument when there is bad news. In their empirical investigation for G7 country pairs, they even find that exchange rates appreciate in response to an increase in monetary policy uncertainty but depreciates following an increase in real volatility (from productivity shocks), with magnitudes that are generally small. Other empirical findings in the literature are also mixed. Bhattarai et al. (2020) reports a nominal depreciation on a small scale (less than half a percentage point) in a panel VAR for fifteen EMEs following an increase in US financial uncertainty as proxied by the VIX. Similarly, Miescu (2019) finds a real depreciation on the scale of $0.6 \%$ for small EMEs. On the other hand, for the Euro area, Colombo (2013) finds that in response to a US EPU shock, the USD/EUR nominal exchange rate appreciates, but its effect are extremely small (less than $0.004 \%$ ).

\subsection{Heterogeneity of shocks}

The overall message from our analysis thus far is that global rather than countryspecific uncertainty is the main driving force of fluctuations in real and financial markets. We also find that financial market and trade flows respond more to global uncertainty, thereby making them important transmission channels of shocks. Upon closer examination of Figs. 5, 6, 7, 8, 9, 10, 11 and 12, however, there still exists some meaningful heterogeneity in the effects of domestic uncertainty shocks which are discussed in turn below.

First, we observe that among all domestic uncertainty measures, financial uncertainty shocks deliver the largest overall contraction in both real and financial variables. Macroeconomic uncertainty is also important, but its impact is more focused on consumption, while political uncertainty matters more for trade flows as well as financial 
markets. It is also interesting to observe that while all domestic uncertainty shocks work through the investment channel, the effects of political and economic policy uncertainty are the most persistent, taking about a year slower than others to subside. Finally, with the exception of the stock market, the impact of economic policy uncertainty appears rather moderate for most variables and is particularly small on trade flows.

An advantage of the LDA approach is that we can also construct separate measures of uncertainty for each topic from its subcomponents. By estimating the empirical VAR again with each of these subcomponents (see Table 2 for a list of the subcomponents), we can gain a deeper understanding about the source and transmission channels of uncertainty shocks. Due to space considerations, the full set of estimation results are placed in Appendix C, but the key findings are summarized below.

First, we find that for macroeconomic uncertainty, the relatively large impact that it has on consumption mainly comes from uncertainty in prices of commodities such as oil and agricultural products. Trade flows and stock market responses to macroeconomic uncertainty, on the other hand, are largely driven by news about production and the growth outlook of the economy. Second, financial uncertainty from capital and credit markets both drives consumption and investment decisions to the same extent, but fluctuations in trade flows mostly stem from uncertainty in credit markets while volatility in asset prices and portfolio flows respond to news in capital markets. Third, we find that all types of uncertainty delivers more or less the same effect on investment $(-0.5 \%)$ except for monetary policy uncertainty which contracts investment by only $-0.25 \%$. Finally, the impact of economic policy uncertainty on the SET index is driven primarily by the monetary policy component since the impact of fiscal policy on financial markets is nonexistent. Instead, the impact of fiscal policy uncertainty is concentrated in trade markets.

Note that it would be difficult to contrast our findings here against past literature because while existing studies have measured and studied different forms of uncertainty (Creal and Wu (2017); Husted et al. (forthcoming) for monetary policy; Ricco et al. (2016) and Mumtaz and Surico (2018)) for fiscal policy uncertainty; and Born and Pfeifer (2014), Julio and Yook (2016) and Azzimonti (2019) for political uncertainty, there has not yet been a single study that compares their effects within a unified framework. The closest strand of literature would be recent work by Carriero et al. (2018a, b, 2019), Ludvigson et al. (forthcoming) and Angelini et al. (2019) that joinlty investigates the impacts of financial and macroeconomic uncertainty shocks, but their focus is more geared toward issues of identification as well as studying their endogenous interactions. Further investigations on the role of different types of uncertainty seem to represent a promising way to go for a more complete understanding of the role of uncertainty shocks.

\subsection{Forecast error variance decompositions}

A substantial body of work in the macroeconomic literature tries to understand the source of business cycle variation. Given the extraordinary events surrounding the "Great Recession," notably the economic contraction and the collapse of the stock 
Table 4 Forecast error variance decomposition of macroeconomic and financial variables to uncertainty shocks

\begin{tabular}{lrrrrrrrr}
\hline & RGDP & C & \multicolumn{1}{l}{ I } & X & IM & SET & NEER & FPI \\
\hline Global & 20.81 & 13.74 & 22.34 & 37.61 & 30.38 & 45.93 & 3.82 & 23.55 \\
Macroeconomic & 13.00 & 21.42 & 26.59 & 10.47 & 14.37 & 11.10 & 10.33 & 7.75 \\
Financial & 12.03 & 20.15 & 29.32 & 11.94 & 7.47 & 13.66 & 10.80 & 2.40 \\
Political & 7.64 & 3.04 & 11.31 & 10.38 & 8.87 & 7.11 & 2.83 & 11.26 \\
Economic policy & 0.99 & 3.15 & 3.88 & 0.33 & 0.73 & 0.36 & 3.63 & 6.45 \\
\hline
\end{tabular}

Reported are the percentages of the forecast error variation in real economic activity and financial variables explained by the various types of uncertainty shocks at 8 quarters. The results for financial variables are obtained from estimating the VAR with RGDP as the real activity variables. The variation in response to global shocks is calculated as the average variation across different types of domestic uncertainty shocks

market, recent studies have cast considerable doubt on traditional sources of macroeconomic and financial market disturbances. In response, uncertainty shocks have been cited as alternative drivers of macroeconomic fluctuations as well as key drivers of volatility in financial markets and capital flows. In this section, we conduct a forecast error variance decomposition (FEVD) to measure the relevance of uncertainty shocks as a source of economic fluctuations and financial market volatility in Thailand. In doing so, we examine the share of variance in our key real activity and financial variables that uncertainty shocks of different types can account for at 8 quarters, a horizon that is relevant to monetary policy and is at a business cycle frequency. ${ }^{15} \mathrm{We}$ are also interested in examining the relative contributions of domestic versus foreign uncertainty shocks to macroeconomic and financial cycles.

Table 4 contains the FEVD results. First, we observe that there is large heterogeneity in the findings, highlighting the importance of differentiating between different types of uncertainty to gain a better perspective about how uncertainty matters for macroeconomic and financial market disturbances. Next we observe that overall, global shocks play a rather large role in explaining variation in macroeconomic and financial variables, with the exception of domestic consumption and the nominal exchange rate which is the least affected. For RGDP, investment and portfolio flows, however, global shocks explain about a fifth of the variation, while strikingly, it drives more than a third of the total variation in trade flows and the SET index, which is considered to be quite substantial.

Turning to examine the role of domestic uncertainty toward business cycle and financial market fluctuations, we find that they also play a significant role. Macroeconomic and financial uncertainty in particular can be considered as key drivers of disturbances in real and financial markets, as they account for approximately a fourth of the forecast error variation in investment and a fifth of the variation in domestic consumption. For trade and financial market sectors, macroeconomic, financial and political uncertainty all account for about $10 \%$ of the variation in exports and imports,

\footnotetext{
15 We also examine the FEVD results at other horizons, but the findings that they deliver do not qualitatively change our discussion of results. Results are available upon request.
} 
stock prices and FPI. Finally, we do not find economic policy uncertainty to be a significant driver of economic nor financial market variation.

Compared to existing studies, the role that we find for domestic uncertainty shocks in explaining real activity fluctuations in Thailand is more or less in line with the literature. For example, Cheng (2017) finds that Korean EPU shocks can explain up to $10 \%$ of the output variation in the short and medium run. For the US, studies also find that domestic uncertainty shocks explain between 10 and $40 \%$ of the variation in real activity and stock prices over short- and long-term horizons (see Bachmann et al. 2013; Jurardo et al. 2015; Caldara et al. 2016; Cascaldi-Garcia and Galvao 2018).

On the impact of foreign shocks, however, our estimated share of forecast error variance is larger than what has been reported in past studies. For example, Cheng (2017) finds that US EPU shocks can explain about one-fifth of the variation in Korean GDP and exports. Mumtaz and Musso (2018) extract a global uncertainty measure from a large set of financial and macroeconomic variables common to 22 OECD countries and finds that global uncertainty explains about $15 \%$ of the volatility of real economic activity growth across countries. Based on taking the first principal component of stock market volatility for 15 largest economies, Kang et al. (2019) show that global financial uncertainty can explain about a fifth of the variation in global growth and global inflation. The relatively high share of fluctuations in real and financial variables for Thailand in response to global shocks, however, is not surprising given that Thailand is a highly open economy in terms of both international trade and financial investment.

\section{Conclusions}

This paper constructs various news and model-based uncertainty measures for Thailand and provides an empirical analysis of their dynamic impact on key real activity and financial market variables. We provide a comprehensive analysis of both the spillover effects of global uncertainty shocks on the Thai economy as well as the local impact of rising macroeconomic, financial, political and economic policy uncertainty.

Our findings suggest that uncertainty of various forms affects the Thai economy through different channels and propagation mechanisms. In general, we find that an increase in uncertainty leads to sudden and large contractions in the financial market, which then gradually transmits to the macroeconomy. Changes in global uncertainty delivers substantial and persistent effects, particularly through segments of the market that have international exposure, namely import and export markets, the stock exchange and foreign portfolio investment. Similarly, the impact of domestic uncertainty toward real activity although not as persistent propagates mainly through investment and trade channels rather than through consumption demand and also leads to substantial declines in financial markets. We also find that among the different types of domestic uncertainty, financial uncertainty matters most for Thailand as a whole, while economic policy uncertainty plays a rather muted role.

We find meaningful heterogeneity across the dynamic responses to the various types of domestic uncertainty. For example, macroeconomic uncertainty that pertains to commodity prices and domestic markets matters most for consumption, while the effects of political uncertainty are most persistent for investment. As for economic 
policy uncertainty, fiscal policy uncertainty is an important driver of fluctuation in trade while monetary policy uncertainty mainly affects financial markets. Similarly, the degree in which uncertainty shocks can explain economic and financial market fluctuations in Thailand can be substantial but depends on the type of shock as wellglobal uncertainty shocks are capable of explaining as high as $45 \%$ of fluctuations in the stock market and a third of the variation in trade flows.

The implications from our results are that policymakers should pay close attention to developments in uncertainty as it is an important driver of fluctuations in business cycles and financial markets. With Thailand being a small open economy that is vulnerable to global uncertainty shocks, policymakers also need to vigilantly monitor uncertainty that spillovers from abroad. Toward future research work, it would be worthwhile to gain a deeper understanding about the multifaceted nature of different types of uncertainty, and studies such as Orlik and Veldkamp (2014) and Kozeniauskas et al. (2018) that tries to uncover the origins of uncertainty shocks are encouraging work in this direction. Furthermore, while this paper has focused solely on a single type of global uncertainty, it would be of interest to investigate how global uncertainty from disparate source countries can impact the economies of EMEs. Finally, it would be fruitful to investigate other macroeconomic and financial channels in which uncertainty shocks could propagate, such as through labor markets (Arellano et al. 2012; Choi and Loungani 2015) and credit markets (Gilchrist et al. 2014; Alessandri and Bottero (2017)).

\section{Appendix A: Model-based uncertainty measure}

The JLN approach estimates uncertainty from a large number of macroeconomic and financial time series based on a diffusion index and stochastic volatility models. We apply the JLN approach to construct macroeconomic and financial uncertainty indices for Thailand. In doing so, we first let $y_{j t}^{C}$ be a variable in either the macro or financial category. Its forecast, $E\left[y_{j t+h}^{C} \mid I_{t}\right]$ can be estimated from the following factor augmented forecasting model:

$$
y_{j t+1}^{C}=\phi_{j}^{y}(L) y_{j t}+\gamma_{j}^{F}(L) \hat{\mathbf{F}}_{t}+\gamma_{j}^{W}(L) \mathbf{W}_{\mathbf{t}}+v_{j t+1}^{y}
$$

where $\phi_{j}^{y}(L), \gamma_{j}^{F}(L), \gamma_{j}^{W}(L)$ are finite-order polynomials. The factors $\hat{\mathbf{F}}_{t}$ are drawn from the information set $I_{t}$ which is approximated by the full dataset which contains both macroeconomic and financial time series variables. ${ }^{16} \mathbf{W}_{\mathbf{t}}$ contains additional predictors that are meant to capture possible nonlinearities such as the squares of the

\footnotetext{
16 To provide a guide for factor estimation, we use the Bai and $\mathrm{Ng}$ (2002) information criterion (IC) to select the number of factors. The IC suggests 3 factors which explains only $21 \%$ of the variation in the dataset, where the first three factors load heavily on real activity measures such as retail sales and the manufacturing production index, the SET index and return on its components, and government bond rates, respectively. Since the variation explained by the three factors are rather low we also consider extracting 18 factors which can explain at least half of the variation of series in the dataset. However, we find whether using 3 or 18 factors provides aggregate uncertainty measures that are not statistically significantly different; thus, we use 3 factors in our empirical investigation.
} 
first component of $\hat{\mathbf{F}}_{t}$. In the model, the prediction error for $y_{j t+1}^{C}, \hat{\mathbf{F}}_{t}, \mathbf{W}_{\mathbf{t}}$ are permitted to have time-varying volatility $\sigma_{j t+1}^{y}, \sigma_{k t+1}^{F}, \sigma_{l t+1}^{W}$, respectively, which generates timevarying uncertainty in the overall series $y_{j t}^{C}$.

From $\mathrm{Eq}(1)$, we compute the forecastable component $E\left[y_{j t+h}^{C} \mid I_{t}\right]$ which form the basis of our uncertainty measures. More specifically, we calculate the forecast error as $V_{j t+h}^{y^{C}}=y_{t+h}^{C}-E\left[y_{j t+h}^{C} \mid I_{t}\right]$, where the conditional volatility of this forecast error $E\left[\left(V_{j t+h}^{y^{C}}\right)^{2} \mid I_{t}\right]$ is then generated based on a parametric stochastic volatility model for the one-step-ahead prediction errors in $y_{j t}^{C}$ and the factors. Then, using a recursive method, we can estimate $E\left[\left(V_{j t+h}^{y^{C}}\right)^{2} \mid I_{t}\right]$ for future horizons $h>1$. As discussed in JLN, the stochastic volatility modeling approach allows for shocks to the second moment of a variable to be independent from the first moment, consistent with theoretical models of uncertainty which presumes the existence of an uncertainty shock that independently affects $y_{j}$.

Finally, uncertainty for the variable $y_{j t}^{C}$ at horizon $h$ can be computed as:

$$
U_{j t}^{y^{C}}(h) \equiv \sqrt{E\left[\left(V_{j t+h}^{y^{C}}\right)^{2} \mid I_{t}\right]}
$$

which measures uncertainty as the conditional volatility of the purely unforecastable component of the h-step-ahead realization of each underlying macroeconomic and financial time series based on available information at time $t$. We follow JLN and assume equal weights $w_{j}=\frac{1}{N_{C}}$ to arrive at the aggregate uncertainty measure: ${ }^{17}$

$$
U_{t}^{y^{C}}(h) \equiv \operatorname{plim}_{N_{\rightarrow \infty}} w_{j} U_{j t}^{y^{C}}(h)
$$

Based on Eq. (3), we compute the macroeconomic and financial uncertainty measures by aggregating the conditional variances of the unforecastable components over variables that belong to the either macroeconomic or financial categories. For both measures, we compute uncertainty for the forecasting horizons $h=4$, but also consider various other horizons for robustness checks. ${ }^{18}$

The underlying dataset to construct Thai economic uncertainty indices comprises of monthly macroeconomic and financial data obtained from the Bank of Thailand and the Stock Exchange of Thailand databases over the 2002M1-2019M12 sample. We choose to construct the series based on monthly data for a wider information set and then construct quarterly uncertainty indices by taking within-quarter averages. In the full dataset, we have 199 macroeconomic series that represent broad categories that describe the macroeconomy (Groups 1-10) and 22 financial series (Group 11)

\footnotetext{
17 Other weighting schemes are also possible such as by employing the principal component analysis (PCA) approach. We follow JLN and construct these measures as part of our robustness checks and find that final indices do not differ significantly.

18 Similar to JLN, we find that the response of economic variables to macroeconomic and financial uncertainty of various horizons do not differ in a significant way.
} 
as listed in Table 5. In the table, each series has one of the following transformation codes which are applied to the data series to ensure stationarity:

\section{Macroeconomic time series transformations}
1: $X_{i t}=X_{i t}^{A}$
2: $X_{i t}=X_{i t}^{A}-X_{i t-1}^{A}$
3: $X_{i t}=\Delta^{2} X_{i t}^{A}$
4: $X_{i t}=\ln \left(X_{i t}^{A}\right)$
5: $X_{i t}=\ln \left(X_{i t}^{A}\right)-\ln \left(X_{i t-1}^{A}\right)$
6: $X_{i t}=\Delta^{2} \ln X_{i t}^{A}$
7: $X_{i t}=\left(X_{i t}^{A}-X_{i t-1}^{A}\right) / X_{i t-1}^{A}$

where $X_{i t}$ denotes the transformed variable $i$ and $X_{i t}^{A}$ is the actual or raw data series. Note that we use the notation $\Delta=1-L$ and $L X_{i t}=X_{i t-1}$.

\section{Financial time series transformations}

For the first five financial time series with transformation code 8 , we follow the method as described below.

- $D \_\log (D I V): \Delta \log D_{t}^{*}$

- $D \_l o g(P): \Delta \log P_{t}$

- D_DIVreinvest : $\Delta \log D_{t}^{r e, *}$

- D_Preinvest : $\Delta \log P_{t}^{r e, *}$

- d-p: $\log \left(D_{t}^{*}\right)-\log \left(P_{t}\right)$

Note that to obtain the dividend and price series, $\left(D_{t}^{*}\right.$ and $\left.P_{t}\right)$, we first construct the return series with dividends $\left(R E T D_{t}\right)$ and excluding dividends $\left(R E T X_{t}\right)$ as: $R E T D_{t}=\frac{P_{t=1}+D_{t+1}}{P_{t}}$ and $R E T X_{t}=\frac{P_{t+1}}{P_{t}}$, and produce a normalized price series based on the recursive rule: $P_{0}=1, P_{t}=P_{t-1} R E T X_{t}$. A dividend series can then be constructed as: $D_{t}=P_{t-1}\left(R E T D_{t}-R E T X_{t}\right)$ where $D_{t}^{*}=\left(D_{t}+D_{t-1}+D_{t-2}+\right.$ $\left.D_{t-3}\right)$.

For dividends and prices under reinvestment, $\left(D_{t}^{r e *}\right.$ and $\left.P_{t}^{r e *}\right)$, we use the recursion $P_{0}^{r e}=1, P_{t}^{r e}=P_{t-1} R E T D_{t}$. Then, dividends under reinvestment can be defined as $D_{t}^{r e}=P_{t-1}^{r e}\left(R E T D_{t}-R E T X_{t}\right)$ where as before, $D_{t}^{r e *}=\left(D_{t}^{r e}+D_{t-1}^{r e}+D_{t-2}^{r e}+\right.$ $\left.D_{t-3}^{r e}\right)$.

Finally, for the remaining 17 financial time series which are industry portfolios, the portfolio returns are constructed from the price and dividend yield series as follows:

$$
R_{i t}=\frac{P_{t+1}+D_{t+1}}{P_{t}}
$$

\section{Appendix B: News-based uncertainty measure}

To construct topic-based uncertainty measures, we adopt Azqueta-Gavaldon (2017) by employing the latent Dirichlet allocation (LDA) method, the most popular topicmodeling approach that has been developed by Blei et al. (2003) to help uncover the 
Table 5 List of macroeconomic and financial variables

\begin{tabular}{lll}
\hline No. & Name and description & Tcode
\end{tabular}

Group 1: National Account Data (Quarterly Series)

$1 \quad$ Real Gross Domestic Product 5

2 Consumption $\quad 5$

$3 \quad$ Government Consumption $\quad 5$

$4 \quad$ Investment 5

$5 \quad$ Exports of goods and services $\quad 5$

$6 \quad$ Imports of goods and services $\quad 5$

Group 2: Output and Income (Monthly Series)

$7 \quad$ PI:Personal Income $\quad 5$

8 MPI: Manufacturing Production Index $\quad 5$

9 MPI_10: Manufacture of food products $\quad 5$

10 MPI_12: Manufacture of tobacco products $\quad 5$

11 MPI_13: Manufacture of textiles $\quad 5$

12 MPI_14: Manufacture of wearing apparel $\quad 5$

13 MPI_15: Manufacture of leather and related products 5

14 MPI_19: Manufacture of coke and refined petroleum products 5

15 MPI_20: Manufacture of chemicals and chemical products 5

16 MPI_22: Manufacture of rubber and plastic products 5

17 MPI_23: Manufacture of other nonmetallic mineral products $\quad 5$

18 MPI_24: Manufacture of basic metals $\quad 5$

19 MPI_25: Manufacture of fabricated metal products, except 5

20 MPI_26: Manufacture of computer and electronic products 5

21 MPI_29: Manufacture of motor vehicles, trailers and semi-trailers 5

22 CAPU_10: Capital utilization of food products 2

23 CAPU_13: Capital utilization of textiles 2

24 CAPU_14: Capital utilization of wearing apparel 2

25 CAPU_15: Capital utilization of leather and related products 2

26 CAPU_17: Capital utilization of paper and paper products 2

27 CAPU_19: Capital utilization of coke and refined petroleum 2 products

28 CAPU_20: Capital utilization of chemicals and chemical products 2

29 CAPU_22: Capital utilization of rubber and plastic products 2

30 CAPU_23: Capital utilization of other nonmetallic mineral products 2

31 CAPU_24: Capital utilization of basic metals 2

32 CAPU_25: Capital utilization of fabricated metal products, except 2

CAPU_26: Capital utilization of computer and electronic products 2 
Table 5 continued

\begin{tabular}{|c|c|c|}
\hline No. & Name and description & Tcode \\
\hline 34 & $\begin{array}{l}\text { CAPU_29: Capital utilization of motor vehicles, trailers and } \\
\text { semi-trailers }\end{array}$ & 2 \\
\hline \multicolumn{3}{|c|}{ Group 3: Labor Markets (Monthly Series) } \\
\hline 35 & Help Wanted & 5 \\
\hline 36 & Help wanted/unemp & 2 \\
\hline 37 & Emp (Total): Employed Total (ThoUSnd) & 5 \\
\hline 38 & $\begin{array}{l}\text { Emp_nonag: Civilian Labor Force: Employed, Non-agricultural } \\
\text { Industries }\end{array}$ & 5 \\
\hline 39 & Unemployment Rate: Unemployment Rate: All workers & 2 \\
\hline 40 & U_dr1m: Unemployment with duration less than 1 month & 5 \\
\hline 41 & U_dr3m : Unemployment with duration between 1 and 2.9 months & 5 \\
\hline 42 & U_dr6m: Unemployment with duration between 3 and 5.9 months & 5 \\
\hline 43 & U_dr9m: Unemployment with duration between 6 and 8.9 months & 5 \\
\hline 44 & $\begin{array}{l}\text { U_dr12m: Unemployment with duration between } 9 \text { and } 11.9 \\
\text { months }\end{array}$ & 5 \\
\hline 45 & U_drmore $12 \mathrm{~m}$ : Unemployment with duration more than 1 year & 5 \\
\hline 46 & Emp total-agri :Total employment in agricultural sector & 5 \\
\hline 47 & Emp privatemanu: Private employment in manufacturing sector & 5 \\
\hline 48 & Emp total-cons:Total employment in construction & 5 \\
\hline 49 & Emp total_trade: Total Employment in Trade & 5 \\
\hline 50 & Emp total_hotelrest:Total employment in hotel and restaurants & 5 \\
\hline 51 & Emp private-fin:Private employments in financial sector & 5 \\
\hline 52 & $\begin{array}{l}\text { Private avg hour: Average working hours per weeks of private } \\
\text { employees }\end{array}$ & 5 \\
\hline 53 & Private earn_hr: Average earning per hour of private employees & 5 \\
\hline 54 & $\begin{array}{l}\text { Avg hr-private manu:Average working hours per weeks of private } \\
\text { manufacturing workers }\end{array}$ & 5 \\
\hline 55 & Avg wage-trade: Average earning per hour for private trade workers & 5 \\
\hline 56 & $\begin{array}{l}\text { Avg wage-fin : Average earning per hour for private financial } \\
\text { workers }\end{array}$ & 5 \\
\hline 57 & $\begin{array}{l}\text { Avg wage-manu: Average earning per hour for private } \\
\text { manufacturing workers }\end{array}$ & 5 \\
\hline
\end{tabular}

\begin{tabular}{lll}
\hline No. & Name and description & Trans Code \\
\hline $\begin{array}{l}\text { Group 4: Housing (Monthly Series) } \\
58\end{array}$ & Fee: Juristic Act and Right Registration Fee for Immovable \\
Property (Millions of Baht) & 5 \\
59 & Land licen: Land Development Licences_-Bangkok Metropolis & 5 \\
60 & Construction Area: Construction Areas Permitted (1000 sqm.) & 5 \\
61 & Land Trans: Land and building Transactions Nationwide (Millions & 5 \\
62 & of Baht) & \\
63 & building licen: Building license & 5 \\
\hline
\end{tabular}


Table 5 continued

\begin{tabular}{|c|c|c|}
\hline No. & Name and description & Trans Code \\
\hline 64 & bld licen-others: Building license in other provinces & 5 \\
\hline 65 & $\begin{array}{l}\text { New hous: New Housing Project in Bangkok Metropolis and } \\
\text { Vicinity (unit) }\end{array}$ & 5 \\
\hline 66 & $\begin{array}{l}\text { housing proj: New Housing in Bangkok Metropolis and Vicinity } \\
\text { (unit) }\end{array}$ & 5 \\
\hline 67 & $\begin{array}{l}\text { apartment: New apartment in Bangkok Metropolis and Vicinity } \\
\text { (unit) }\end{array}$ & 5 \\
\hline 68 & $\begin{array}{l}\text { self built housing: New self-built housing in Bangkok Metropolis } \\
\text { and Vicinity (unit) }\end{array}$ & 5 \\
\hline 69 & credit outstanding: Property Credit Outstanding (Millions of Baht) & 5 \\
\hline 70 & re credit: Real Estate Development Credit & 5 \\
\hline 71 & personal housing credit:Personal Housing Credit & 5 \\
\hline \multicolumn{3}{|c|}{ Group 5: Consumption, Orders and Inventories (Monthly Series) } \\
\hline 72 & bsi: Business survey index & 2 \\
\hline 73 & bsi_perf: Business survey index Performance & 2 \\
\hline 74 & bsi_order: Business survey index Total Order Book & 2 \\
\hline 75 & bsi_invest: Business survey index Investment & 2 \\
\hline 76 & bsi_employment: Business survey index Employment & 2 \\
\hline 77 & bsi_cost : Business survey index Production Costs (Invert) & 2 \\
\hline 78 & bsi_3 month: Expected Business survey index over 3 month horizon & 2 \\
\hline 79 & Retail Sales Index & 5 \\
\hline 80 & Retail: Motor: Retail sales of motor vehicles and automotive fuel & 5 \\
\hline 81 & Retail: Nondu: Retail sales of non-durable goods & 5 \\
\hline 82 & Retail: Du: Retail sales of durable goods & 5 \\
\hline 83 & $\begin{array}{l}\text { Retail: Store: Retail sales of department stores, supermarkets and } \\
\text { general stores }\end{array}$ & 5 \\
\hline 84 & Wholesales Index & 5 \\
\hline 85 & whole sale: non du: Wholesales of non-durable goods & 5 \\
\hline 86 & whole sale: du: Wholesales of durable goods & 5 \\
\hline 87 & whole sale: int : Wholesales of intermediate goods & 5 \\
\hline 88 & VAT_-Gross Value Added Tax at 2000 prices (Million baht) & 5 \\
\hline 89 & Sales: Automotives: Domestic automobiles sales & 5 \\
\hline 90 & Sales: Clothes: Retail sale of clothing, footware and leather articles & 5 \\
\hline 91 & Sales: Food: Retail sale of food in specialized store & 5 \\
\hline 92 & Sales: Bev: Retail sale of beverages in specialized store & 5 \\
\hline 93 & Sales: Tobacco: Retail sale of tobacco products in specialized stores & 5 \\
\hline 94 & $\begin{array}{l}\text { Sales: Electronics appliances: Retail sale of electrical household } \\
\text { appliances in specialized stores }\end{array}$ & 5 \\
\hline 95 & PII: Private Investment Index & 5 \\
\hline 96 & Sales: Construction: Construction material sales index & 5 \\
\hline 97 & Import: Capital: Imports of capital goods at 2010 prices & 5 \\
\hline
\end{tabular}


Table 5 continued

\begin{tabular}{|c|c|c|}
\hline No. & Name and description & Trans Code \\
\hline 98 & Sales: Machine: Domestic machinery sales at 2010 prices & 5 \\
\hline 99 & PCI : Personal Consumption Index & 5 \\
\hline 100 & Sales: Passenger Cars: Sales of passenger cars (units) & 5 \\
\hline 101 & Sales: Motorcycle Sales: Sales of motorcycles (units) & 5 \\
\hline 102 & Sales: Commercial Cars: Sales of commercial cars (units) & 5 \\
\hline 103 & Gas Index: Sales of benzene, gasohol and diesel index & 5 \\
\hline 104 & Electricity: Household electricity consumption index & 5 \\
\hline 105 & Import: Clothes: Import of textiles index & 5 \\
\hline 106 & Domestic Car Sales: Domestic automobiles sales (units) & 5 \\
\hline \multicolumn{3}{|c|}{ Group 6: Money and Credit (Monthly Series) } \\
\hline 107 & M1: Narrow money & 7 \\
\hline 108 & M2: Broad money & 7 \\
\hline 109 & Currency: Currency held by the public & 7 \\
\hline 110 & Banknotes in Circulation & 7 \\
\hline 111 & Deposit & 7 \\
\hline 112 & Narrow Money & 7 \\
\hline 113 & Currency Held by Depository Corp.-Commercial Banks & 7 \\
\hline 114 & Transferable Deposits at Depository Corp.-Commercial Banks & 7 \\
\hline 115 & Quasi-money & 7 \\
\hline 116 & MLR: minimum loan rate (Min) & 2 \\
\hline 117 & MLR minimum loan rate (Max) & 2 \\
\hline 118 & MRR: minimum retail rate (Min) & 2 \\
\hline 119 & MRR: minimum retail rate (Max) & 2 \\
\hline 120 & Government bonds (Total) & 6 \\
\hline 121 & Treasury bills (Total) & 7 \\
\hline 122 & Promissory notes (Total) & 7 \\
\hline 123 & State enterprise bonds (total) & 6 \\
\hline 124 & BOT-bond : Bank of Thailand bonds & 6 \\
\hline 125 & $\begin{array}{l}\text { Government debt securities held by non-financial market mutual } \\
\text { funds }\end{array}$ & 6 \\
\hline 126 & Outstanding government debt security & 6 \\
\hline 127 & Total deposits outstanding of Commercial Banks & 6 \\
\hline 128 & Deposits turnover ratio of Commercial Banks & 2 \\
\hline 129 & Government bonds Short-term 1 year & 6 \\
\hline 130 & Government bonds Medium-term 1-5 years & 6 \\
\hline 131 & Government bonds Long-term 5 year up & 6 \\
\hline 132 & Government promissory notes & 6 \\
\hline 133 & State enterprise bonds Short-term 1 year & 6 \\
\hline 134 & State enterprise bonds Medium-term 1-5 years & 6 \\
\hline 135 & State enterprise bonds Long-term 5 year up & 6 \\
\hline
\end{tabular}


Table 5 continued

\begin{tabular}{lll}
\hline No. & Name and description & Trans Code \\
\hline 136 & State enterprise promissory notes Short-term 1 year & 6 \\
137 & New issuances of domestic securities & 6 \\
138 & New issuances of domestic public sector securities & 6 \\
139 & New issuances of domestic private sector securities & 6 \\
140 & Authorized Capital of Newly Registered Companies & 6
\end{tabular}

Group 7: Bonds and Exchange Rate Measures (Monthly Series)

$141 \quad$ NEER: Nominal effective exchange rate 5

142 REER: Real effective exchange rate 5

143 inter_overnight: Interbank overnight lending rates 2

144 repo_1day: Bilateral repurchase rate (1 day) 2

145 repo_7days: Bilateral repurchase rate (7 days) 2

146 repo_14days: Bilateral repurchase rate (14 days) 2

147 Thai Baht implied interest rate (1 month) 2

$148 \quad$ Thai Baht implied interest rate (3 months) 2

149 Thai Baht implied interest rate (6 months) 2

$150 \quad$ tThai Baht implied interest rate (12 months) 2

$151 \quad$ Government bond yield (1 year) 2

$152 \quad$ Government bond yield (2 years) 2

$153 \quad$ Government bond yield (3 years) 2

$154 \quad$ Government bond yield (5 years) 2

$155 \quad$ Government bond yield (7 years) 2

$156 \quad$ Government bond yield (10 years) 2

$157 \quad$ Government bond yield (12 years) 2

$158 \quad$ Government bond yield (14 years) 2

Group 8: Prices (Monthly Series)

$159 \quad$ CPI : Consumer price index 5

160 CPI-food: Consumer price index food and non-alcoholic beverages 5

161 CPI-apparel: Consumer price index apparel and foodwear 5

162 CPI-housing: Consumer price index housing and furnishing 5

163 CPI-med: Consumer price index medical and personal care 5

164 CPI-trans: Consumer price index transportation and communication $\quad 5$

165 CPI-recre: Consumer price index recreation and education 5

166 CPI-tobacco: Consumer price index tobacco and alcoholic 5

167 CPI-rawfood: Consumer price index raw food 5

168 CPI-energy: Consumer price index energy 5

169 CPI-ex food energy: Consumer price index excluding food and 5

170 CPI-ex food energy rent: Consumer price index excluding energy 5 and rent 
Table 5 continued

\begin{tabular}{lll}
\hline No. & Name and description & Trans Code \\
\hline 171 & PPI : Producer price index & 6 \\
172 & PPI_agri: Producer price index agricultural products & 6 \\
173 & PPI_mining: Producer price index mining products & 6 \\
174 & PPI_manu: Producer price index manufactured products & 6 \\
175 & price_cons: Price of construction materials index & 6 \\
176 & price_wood: Price of construction materials_wood & 6 \\
177 & price_cement: Price of manufacturing goods_mixed cement 50 kgs. & 6 \\
178 & price_metal: Price of construction materials_metal & 6 \\
179 & price_diesel: Price of manufacturing goods_diesel & 6 \\
180 & price_fueloil: Price of manufacturing goods_fuel oil & 6 \\
181 & price_sugar: Price of manufacturing goods_white sugar (1 kg.) & 6 \\
182 & price_rice: Wholesale price of 100\% rice in Bangkok Metropolis & 6 \\
183 & price_rubber: Wholesale price of ribbed smoked sheet rubber in & 6
\end{tabular}

Group 9: Stock Market Indices (Monthly Series)

184 SET index: Stock Exchange of Thailand Index 5

185 SET Food Index 5

$186 \quad$ SET Bank Index 5

187 SET Energy Index 5

$188 \quad$ SET 50: SET 50 Index 5

Group 10: Trade (Monthly Series)

189 Ex-volume: Export volume 5

$190 \quad$ Im-volume: Import volume 5

191 Im-cons: Import-Consumer Goods: Volume 5

192 Im-rawmat: Import-Raw Materials: Volume 5

193 Im-cap: Import—Capital Goods: Volume 5

194 Ex-agri: Export-Agricultural Products: Volume 5

195 Ex-fish: Export—Fishery Products: Volume 5

196 Ex-mfgs: Export-mfgs: Volume 5

$197 \quad$ Import goods excluding gold 4

$198 \quad$ Occupancy Rate 5

199 Tourists 5

Group 11: Financial Variables (Monthly Series)

200 D_log(DIV): Dividend series based on 8

201 D_log(P): Price series based on $\quad 8$

202 D_DivReinvest: Dividend under reinvestment based on 8

203 D_Preinvest: Price under reinvestment based on 8

204 d-p: Dividend to price ratio based on 8

$205 \quad$ AutoReturn: Automotive industry portfolio $\quad 8$

$206 \quad$ FoodReturn: Food industry portfolio $\quad 8$ 
Table 5 continued

\begin{tabular}{lll}
\hline No. & Name and description & Trans Code \\
\hline 207 & FashionReturn: Fashion industry portfolio & 8 \\
208 & HomeReturn: Home industry portfolio & 8 \\
209 & PersonReturn: Personal goods industry portfolio & 8 \\
210 & FinanceReturn: Finance industry portfolio & 8 \\
211 & InsuranceReturn: Insurance industry portfolio & 8 \\
212 & PetroReturn: Petroleum industry portfolio & 8 \\
213 & PKGReturn: Packaging industry portfolio & 8 \\
214 & PropertyReturn: Property industry portfolio & 8 \\
215 & ENERGReturn: Energy industry portfolio & 8 \\
216 & CommReturn: Commerce industry portfolio & 8 \\
217 & HELTHReturn : Healthcare industry portfolio & 8 \\
218 & MEDIAReturn : Media industry portfolio & 8 \\
219 & TourismReturn: Tourism industry portfolio & 8 \\
220 & TranReturn: Transportation industry portfolio & 8 \\
221 & ETRONReturn: Electronics industry portfolio & 8
\end{tabular}

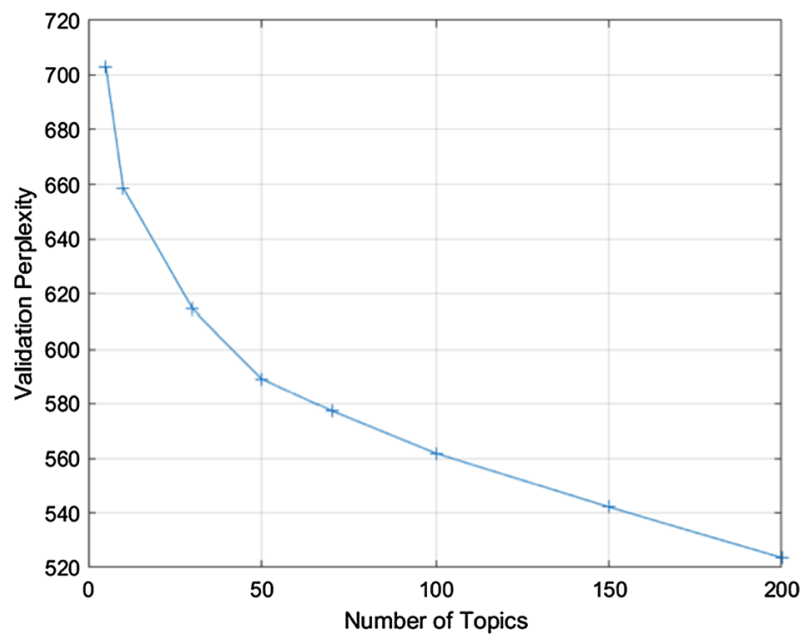

Fig. 13 Number of topics and perplexity. Note Validation perplexity is based on the log probabilities of randomly selected articles in a 10\% test set. Details on calculations can be found in Wallach et al. (2009)

underlying topics in the Thai-language newspapers. The steps that we follow are as outlined below:

(i) Select articles in the economics and business section that contain any of the following keywords: [ "uncertain(ty)," "delayed," "conflict," "crisis," "postpone," "procrastinate," "confused," "unsure," "bankrupt," "unclear," "risk(y)," "halted," "ambiguous"\}. 
(ii) Screen out articles that are too short (less than 50 words) or too long (more than 1000 words), which leaves us with a total of remaining 91,400 news articles. Based on our reading in the Thai newspapers, we find that very short articles often contain uninformative news including advertisement and gossip sections while very long articles contain too many different topics that could potentially introduce noise into the estimation process. Note that, on this issue, other refinement process can be applied. For example, Husted et al. (2020) construct monetary policy uncertainty using proximity refinement by restricting uncertainty words to be within 5-20 words of the phrase 'federal reserve' or 'monetary policy'.

(ii) Apply standard preprocessing by removing stop words and punctuation, lemmatization and stemming.

(iii) Employ the LDA approach to uncover underlying topics. The LDA assumes a generative process with the following joint distribution:

$$
p(\theta, z, w \mid \alpha, \beta)=p(\theta \mid \alpha) \prod_{n=1}^{N} p\left(z_{n} \mid \theta\right) p\left(w_{n} \mid z_{n}, \beta\right)
$$

where each document has a multinomial distribution $\theta$ of topics. A document's topic distribution is randomly sampled from a Dirichlet distribution with $\alpha$ as a parameter governing the concentration, $\beta=\left\{\beta_{1}, \ldots, \beta_{k}\right\}$ as the topic-word probabilities of $K$ topics, and $z=\left\{z_{1}, \ldots, z_{N}\right\}$ and $w=\left\{w_{1}, \ldots, w_{N}\right\}$ are sets of $N$ topics and words, respectively. In this study, we set $\alpha=50 / K$ and $\beta=0.1$ as suggested by Griffiths and Steyvers (2004) and compare the goodness of fit of models with different values of $K$. The goodness of fit for each model is based on calculating the perplexity value as proposed by Wallach et al. (2009). ${ }^{19}$

Figure 13 shows the model's evaluation based on the perplexity value for $K$ between 5 and 200. We find that the goodness of fit improves monotonically with a larger $K$. Therefore, we also need to consider the interpretability of the topics derived from the model based on our own subjective judgment. Too few topics can produce results that are too broad, while selecting too many topics can lead to too detailed and redundant topics. In our case, we find that the topics become very specific and semantically less meaningful when $K$ is above 50 . Thus, we choose $K=50$ which yields the most interpretable result. Applying a subjective judgment for $K$ is a valid approach that has also been carried out by Larsen (2021), in which he picked $K=80$ to construct measures of economic uncertainty using the LDA method for Norway. In addition, as cited in Larsen (2021), Chang et al. (2009) conclude that "practitioners developing topic models

\footnotetext{
19 We follow Wallach et al. (2009) and calculate the perplexity value as perplexity $(W)=$ $\exp \left\{\frac{\sum \log P\left(w_{d} \mid \Phi, \alpha\right)}{\sum N_{d}}\right\}$, where $W$ is the test set which contains a random selection of articles $w_{d}$ which amount to $10 \%$ of all articles in the full dataset. For each article $w_{d}$, the probability $P\left(w_{d} \mid \Phi, \alpha\right)$ is computed as $P\left(w_{d} \mid \Phi, \alpha\right)=\int d \theta P\left(w_{d} \mid \theta, \Phi\right) P(\theta \mid \alpha)$, in which the integral is approximated via the iterated pseudo-count method. $\sum N_{d}$ is the total number of words in the whole set and parameters $\Phi$ and $\alpha$ are learned from the training set.
} 
should thus focus on evaluations that depend on real-world task performance rather than optimizing likelihood-based measures" (p. 296).

(iv) Construct the uncertainty index for each topic based on the number of articles describing uncertainty for each topic. More specifically, we first label each article $d$ with its most likely topic (the topic with the highest probability $\theta_{d}$ ). The index is then the estimated topic proportion for each topic within a quarter.

Appendix C: Impulse response analysis of domestic uncertainty subcomponents

See Figs. 14, 15, 16, 17, 18 19, 20, 21, 22, 23, 24 and 25. 

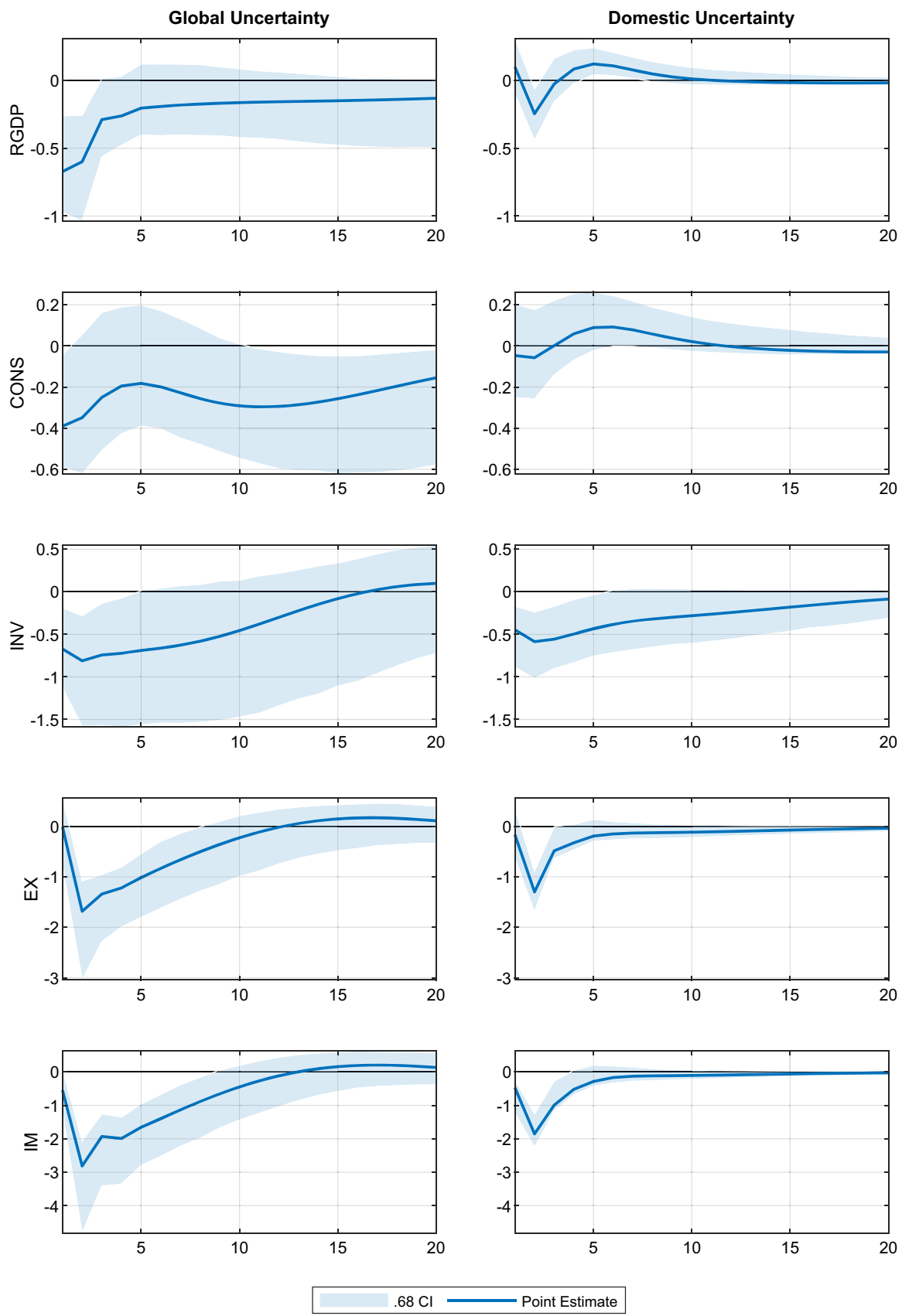

Fig. 14 Impulse responses of macroeconomic variables to global uncertainty and domestic macroeconomic uncertainty shocks (production and growth outlook). Note Plotted are the impulse responses to global and domestic macroeconomic uncertainty shocks. Shaded regions correspond to $68 \%$ standard error bands 

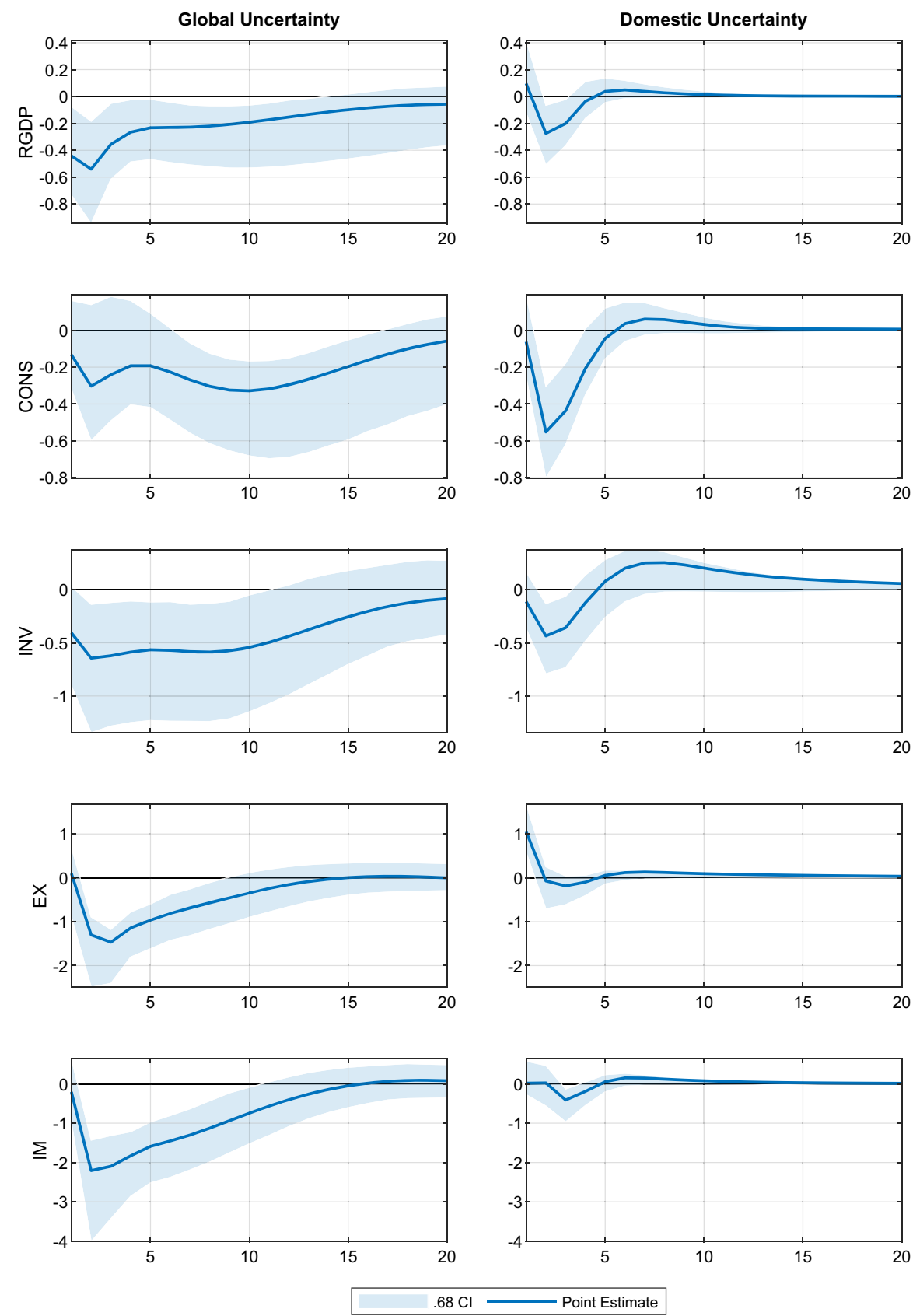

Fig. 15 Impulse responses of macroeconomic variables to global uncertainty and domestic macroeconomic uncertainty shocks (commodity prices and agricultural products). Note Plotted are the impulse responses to global and domestic macroeconomic uncertainty shocks. Shaded regions correspond to $68 \%$ standard error bands 

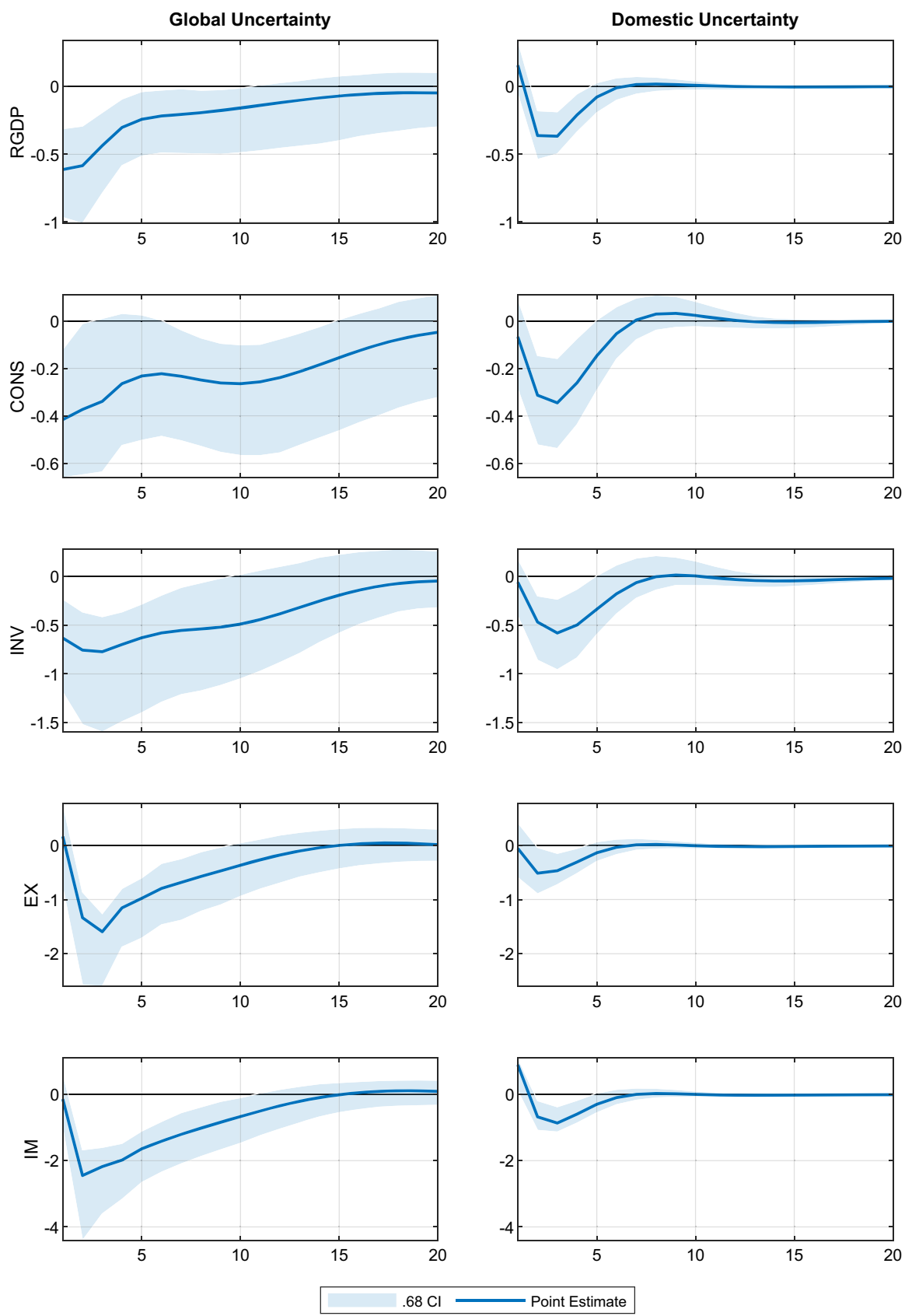

Fig. 16 Impulse responses of macroeconomic variables to global uncertainty and domestic financial uncertainty shocks (capital markets). Note Plotted are the impulse responses to global and domestic macroeconomic uncertainty shocks. Shaded regions correspond to $68 \%$ standard error bands 

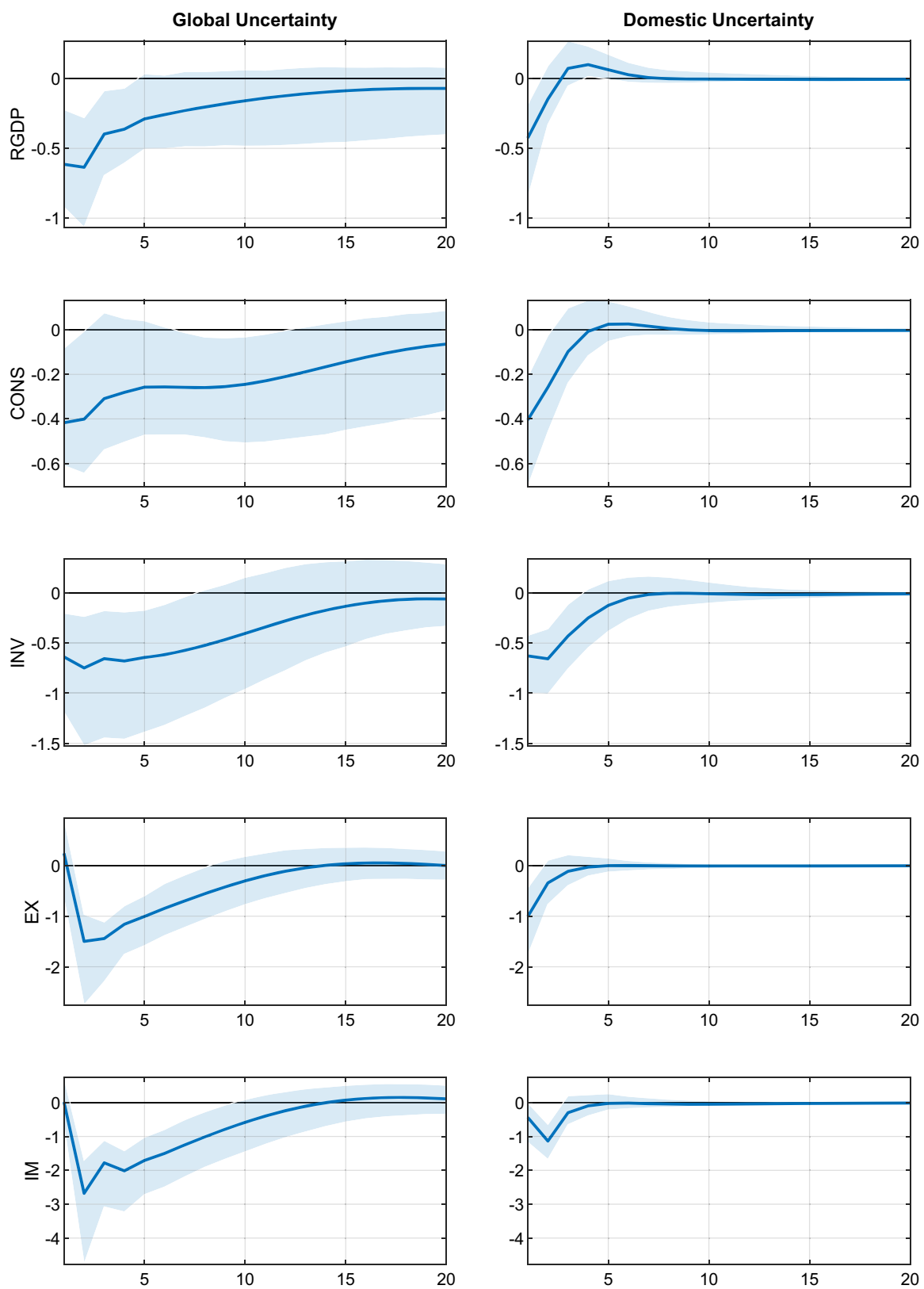

$.68 \mathrm{Cl}$

Point Estimate

Fig. 17 Impulse responses of macroeconomic variables to global uncertainty and domestic financial uncertainty shocks (credit markets). Note Plotted are the impulse responses to global and domestic macroeconomic uncertainty shocks. Shaded regions correspond to $68 \%$ standard error bands 

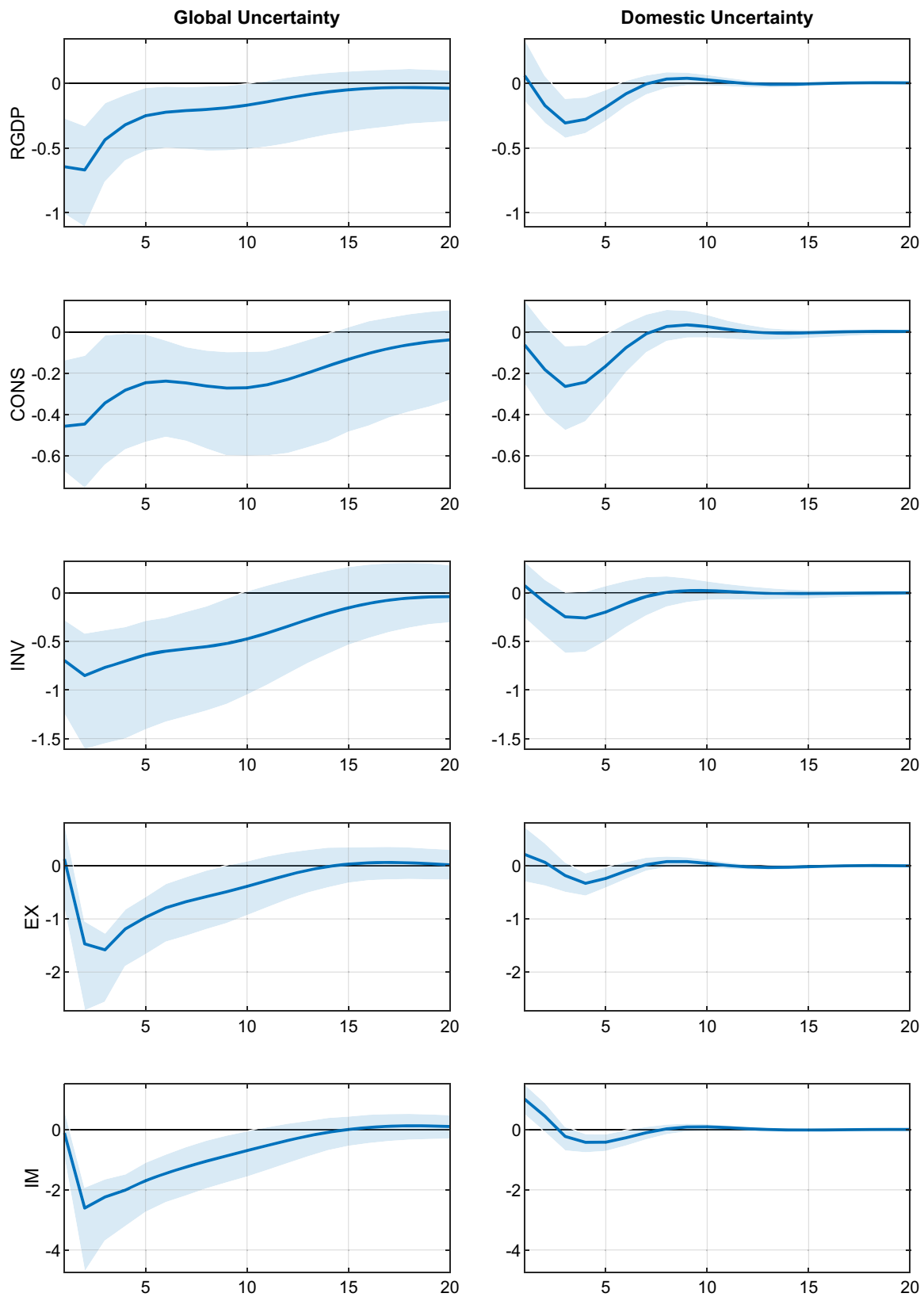

Fig. 18 Impulse responses of macroeconomic variables to global uncertainty and domestic monetary policy uncertainty shocks. Note Plotted are the impulse responses to global and domestic macroeconomic uncertainty shocks. Shaded regions correspond to $68 \%$ standard error bands 

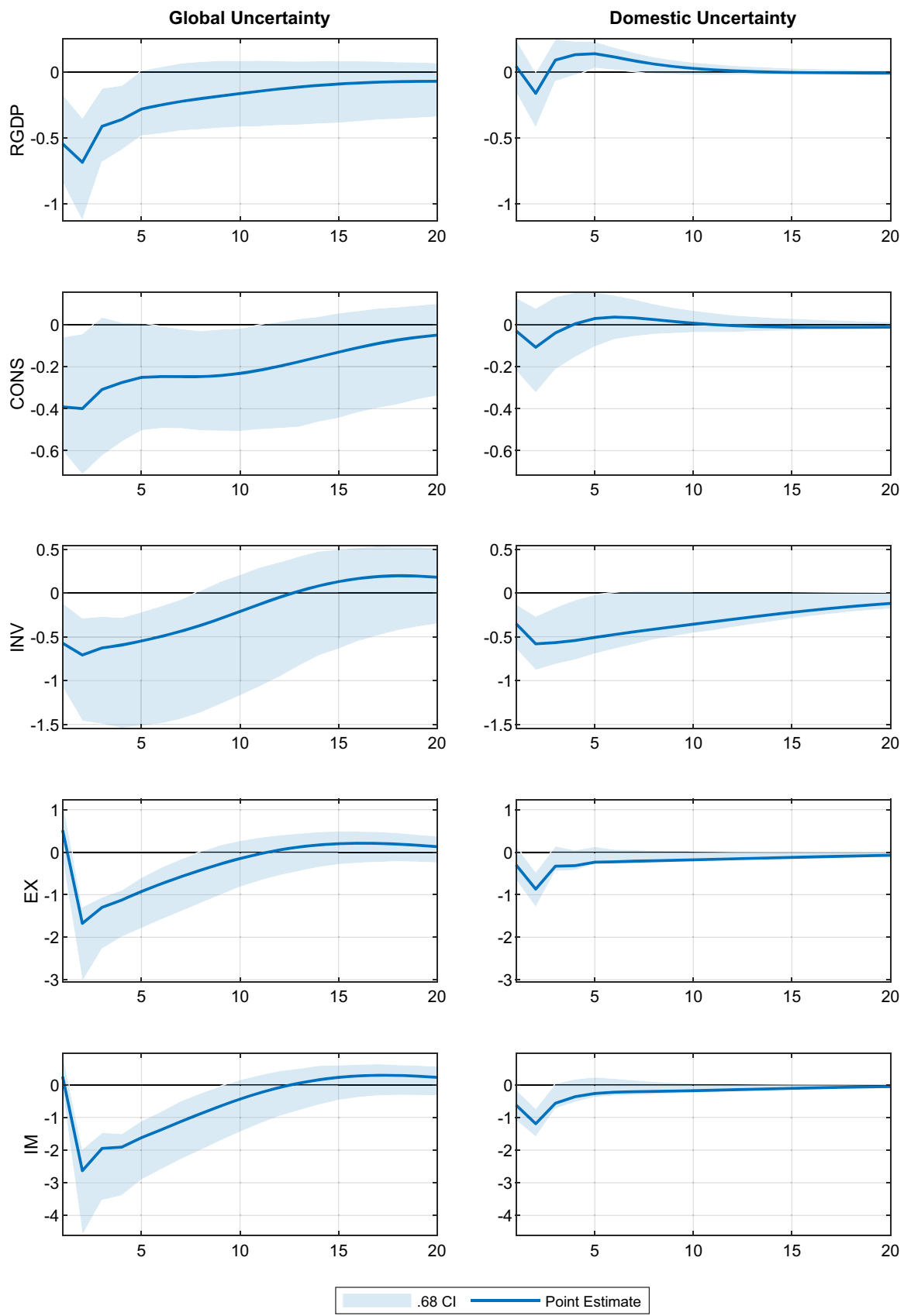

Fig. 19 Impulse responses of macroeconomic variables to global uncertainty and domestic fiscal uncertainty shocks. Note Plotted are the impulse responses to global and domestic macroeconomic uncertainty shocks. Shaded regions correspond to $68 \%$ standard error bands 

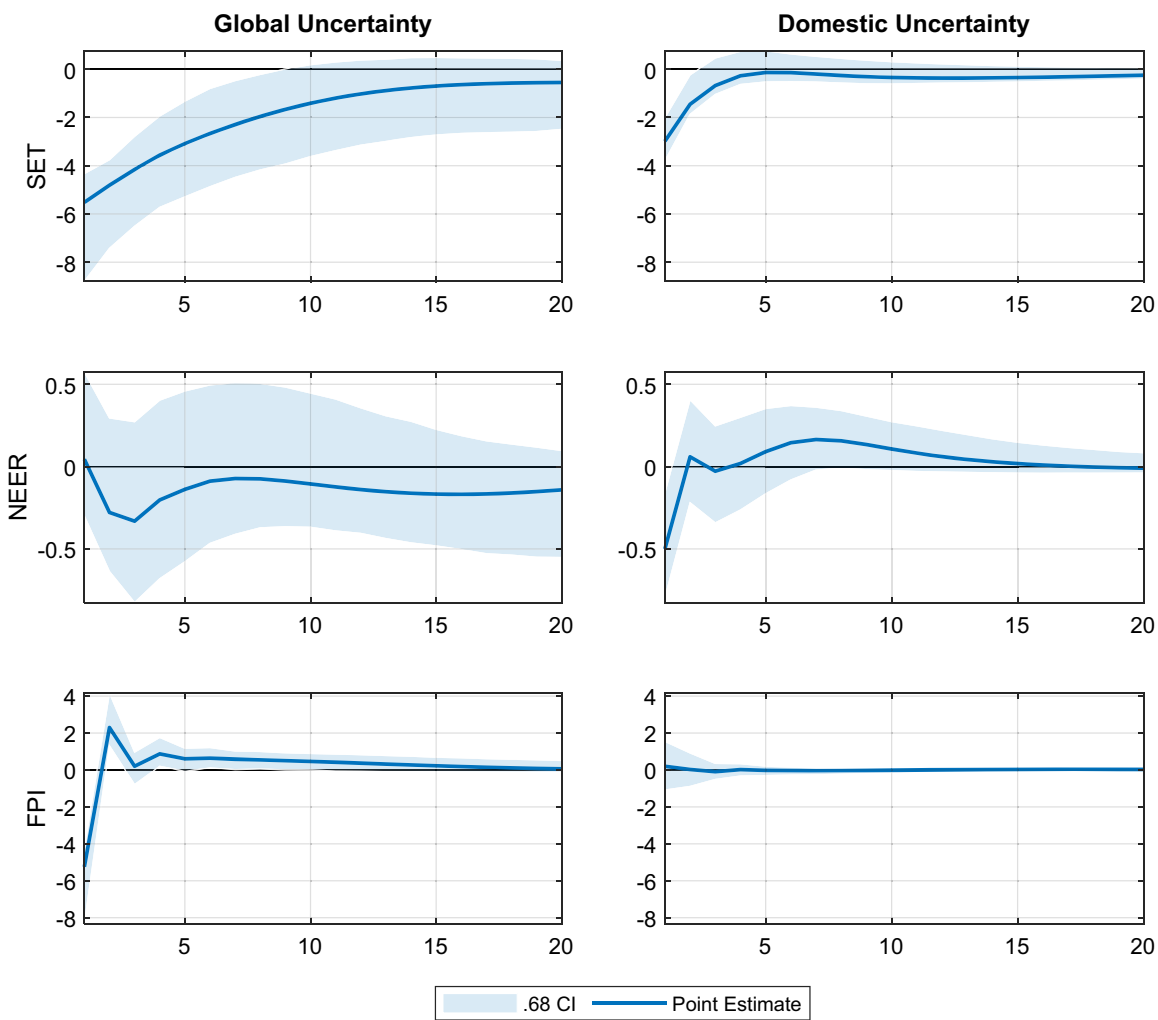

Fig. 20 Impulse responses of financial variables to global uncertainty and domestic macroeconomic uncertainty shocks (production and growth outlook). Note Plotted are the impulse responses to global uncertainty and domestic financial uncertainty shocks. Shaded regions correspond to $68 \%$ standard error bands 

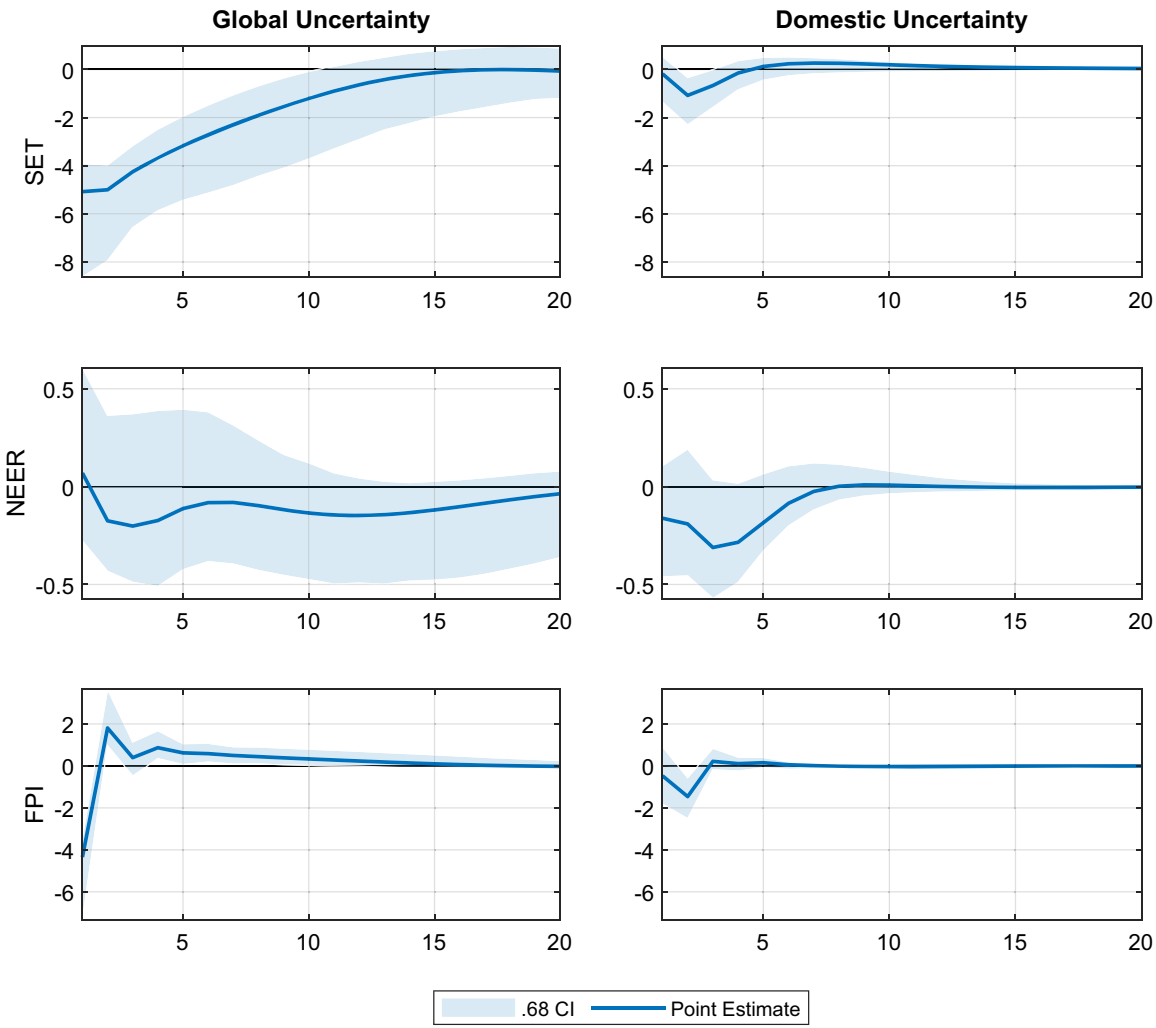

Fig. 21 Impulse responses of financial variables to global uncertainty and domestic macroeconomic uncertainty shocks (commodity prices and agricultural products). Note Plotted are the impulse responses to global uncertainty and domestic financial uncertainty shocks. Shaded regions correspond to $68 \%$ standard error bands 

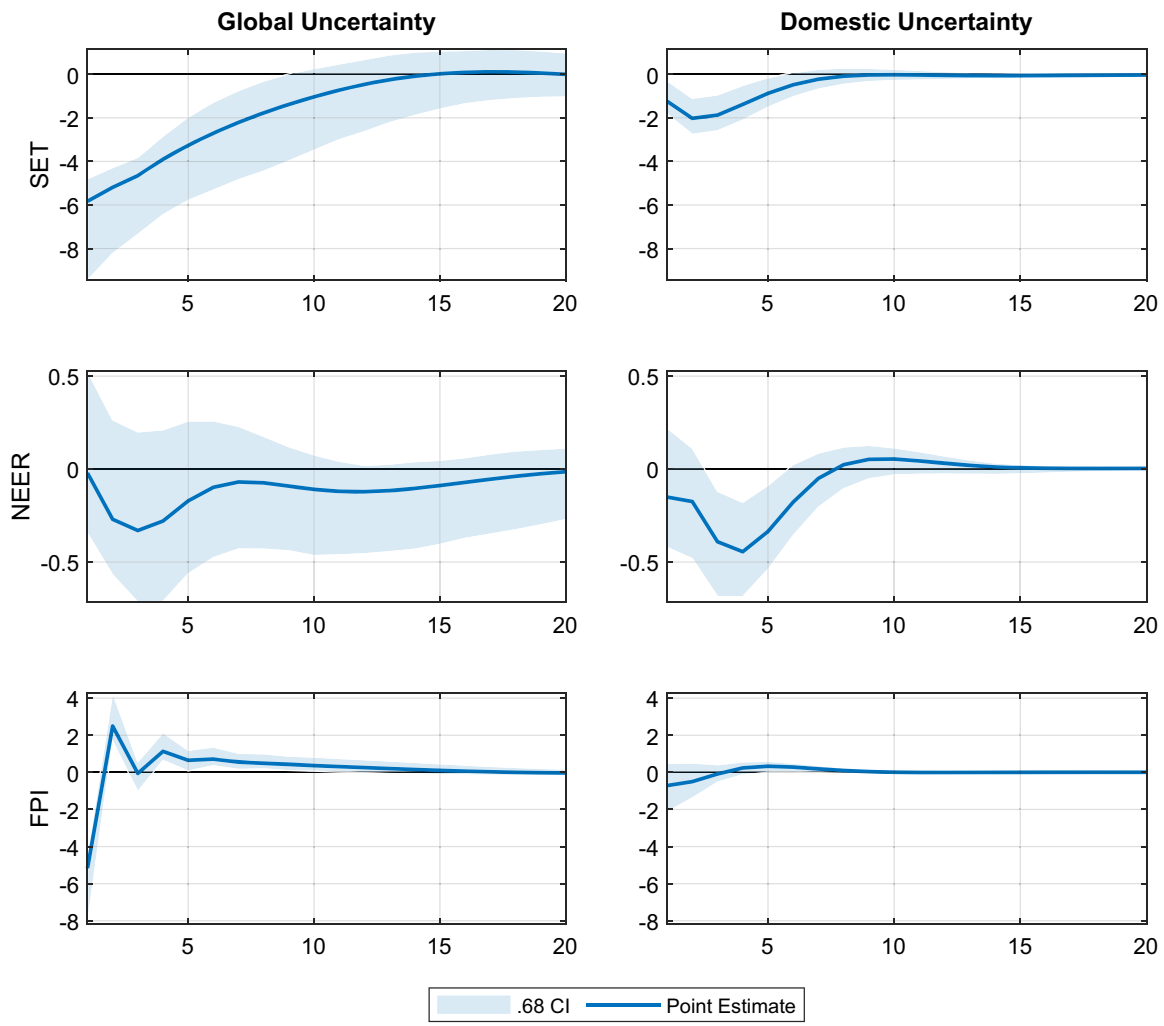

Fig. 22 Impulse responses of financial variables to global uncertainty and domestic financial uncertainty shocks (capital markets). Note Plotted are the impulse responses to global uncertainty and domestic financial uncertainty shocks. Shaded regions correspond to $68 \%$ standard error bands 

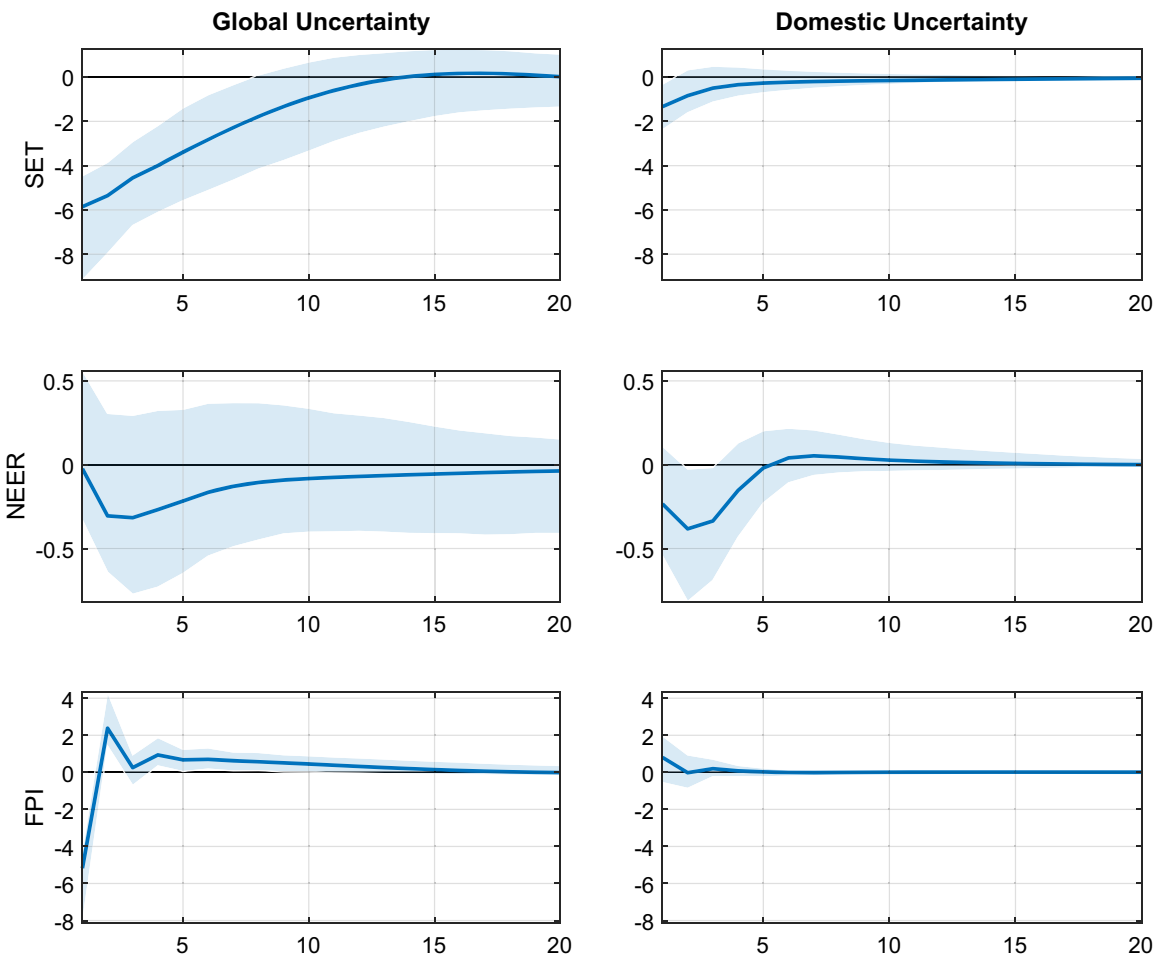

$.68 \mathrm{Cl}=$ Point Estimate

Fig. 23 Impulse responses of financial variables to global uncertainty and domestic financial uncertainty shocks (credit markets). Note Plotted are the impulse responses to global uncertainty and domestic financial uncertainty shocks. Shaded regions correspond to $68 \%$ standard error bands 

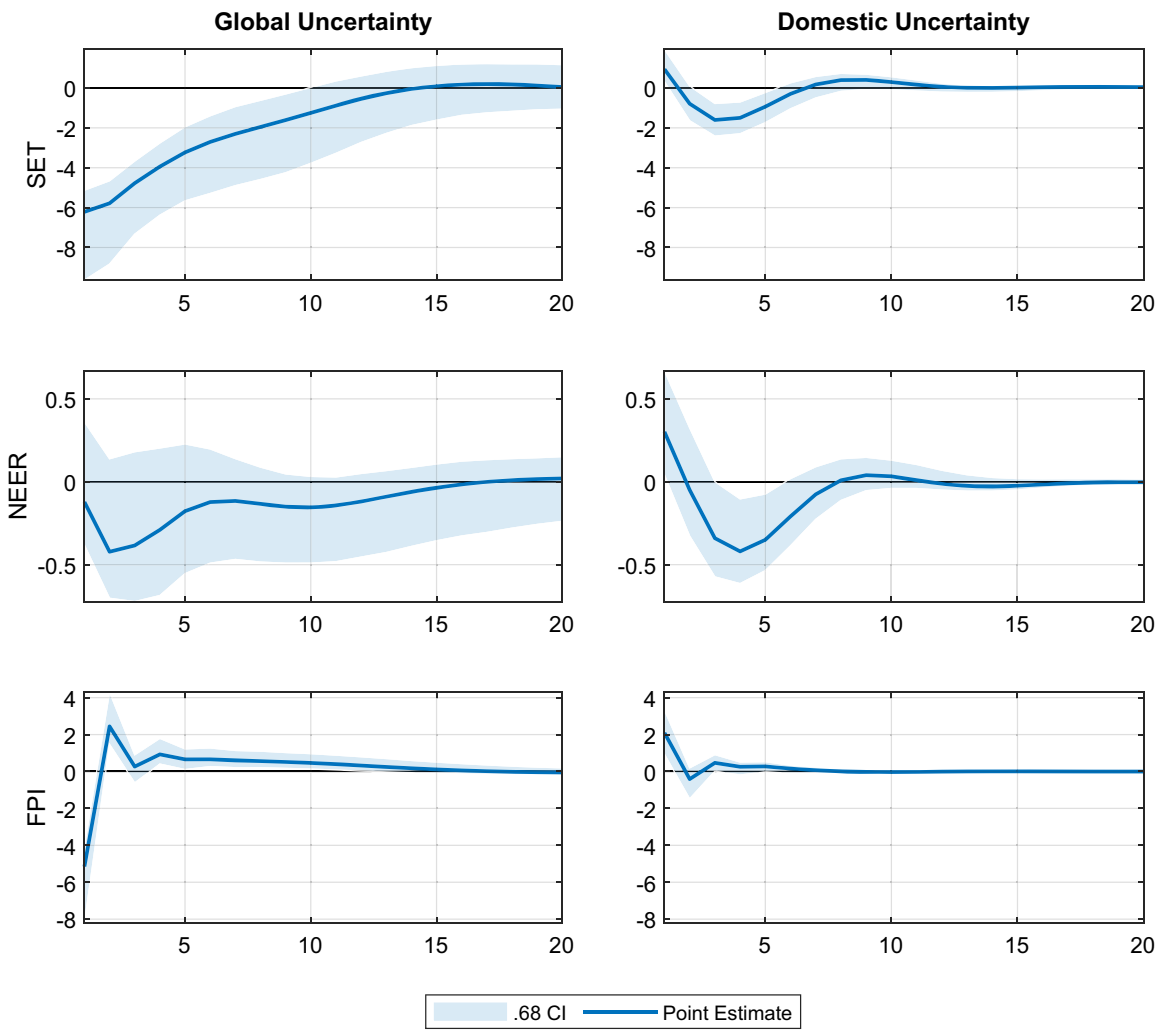

Fig. 24 Impulse responses of financial variables to global uncertainty and domestic monetary policy uncertainty shocks. Note Plotted are the impulse responses to global uncertainty and domestic financial uncertainty shocks. Shaded regions correspond to $68 \%$ standard error bands 

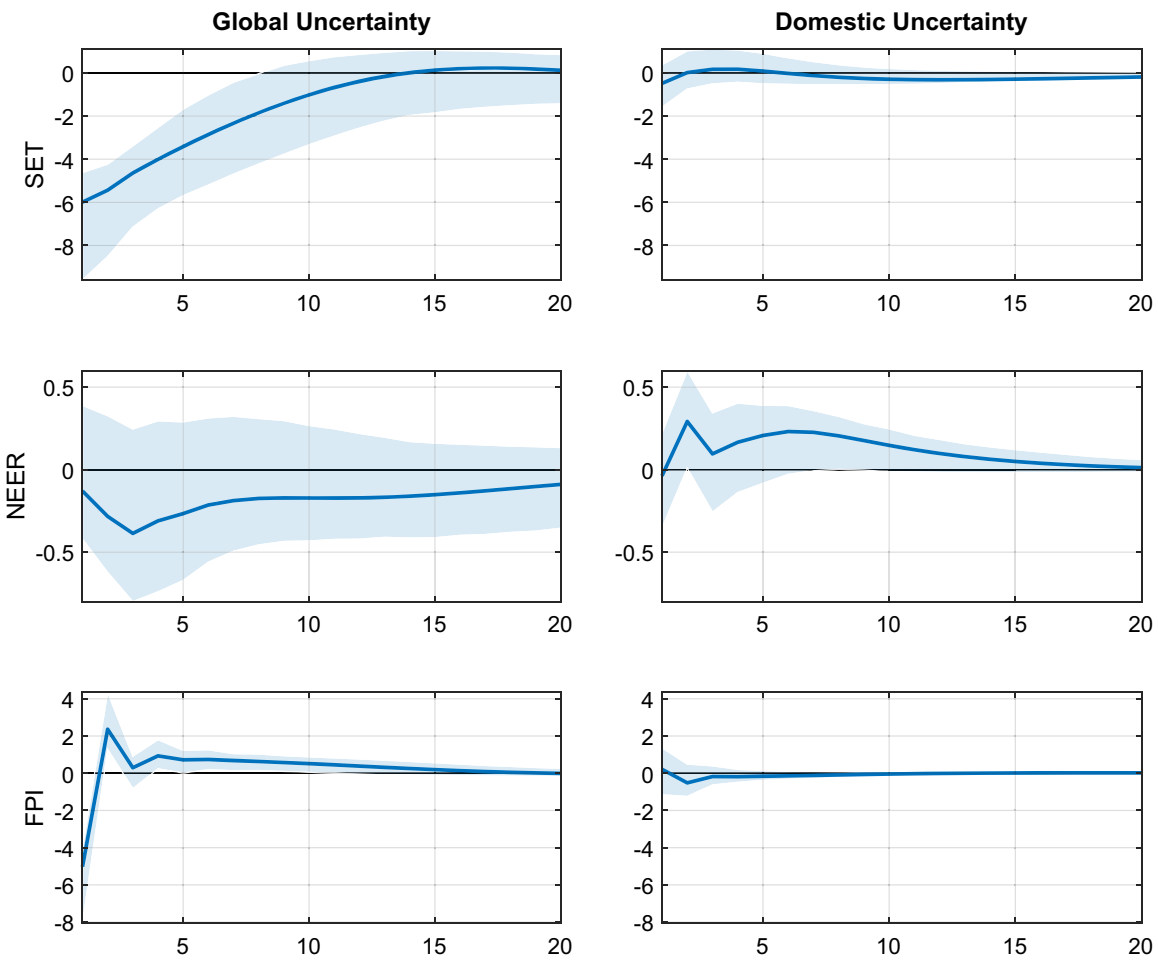

$.68 \mathrm{Cl} \longrightarrow$ Point Estimate

Fig. 25 Impulse responses of financial variables to global uncertainty and domestic fiscal uncertainty shocks. Note Plotted are the impulse responses to global uncertainty and domestic financial uncertainty shocks. Shaded regions correspond to $68 \%$ standard error bands

\section{References}

Abel J, Rich R, Song J, Tracy J (2016) The measurement and behavior of uncertainty: evidence from the ECB survey of professional forecasters. J Appl Econom 31(3):533-550

Ahir H, Nicholas B, Davide F (2021) What the continued global uncertainty means for you. IMF Blog, January 19

Alessandri P, Bottero M (2017) Bank lending in uncertain times. BCAM Working Papers 1703, Birkbeck Centre for Applied Macroeconomics

Alessandri P, Mumtaz H (2019) Financial regimes and uncertainty shocks. J Monet Econ 101:31-46

Angelini G, Bacchiocchi E, Caggiano G, Fanelli L (2019) Uncertainty across volatility regimes. J Appl Econom 34(3):437-455

Arbatli EC, Davis SJ, Ito A, Miake N, Saito I (2019) Policy uncertainty in Japan. Hoover Institution Economics Working Papers No. 19109

Arellano C, Bai Y, Kehoe P, (2012) Financial frictions and fluctuations in volatility. Staff Report 466, Federal Reserve Bank of Minneapolis

Azqueta-Gavaldon A (2017) Developing news-based economic policy uncertainty index with unsupervised machine learning. Econ Lett 158:47-50

Azzimonti M (2019) Does partisan conflict deter FDI inflows to the US? J Int Econ 120:162-178

Bachmann R, Elstner S, Sims E (2013) Uncertainty and economic activity: evidence from business survey data. Am Econ J Macroecon 5(2):217-224 
Bai J, Ng S (2002) Determining the number of factors in approximate factor models. Econometrica 701:191221

Baker M, Foley CF, Wurgler J (2009) Multinationals as arbitrageurs: the effect of stock market valuation on foreign direct investment. Rev Financ Stud 22:337-369

Baker S, Bloom N, Davis SJ, Wang X (2013) A Measure of economic policy uncertainty for China, University of Chicago Working Paper

Baker SR, Bloom N, Davis SJ (2016) Measuring economic policy uncertainty. Quart J Econ 131(4):15931636

Balta N, Fernández V, Ruscher E (2013) Assessing the impact of uncertainty on consumption and investment. Eur Comm Q Rep Euro Area 12(2):7-16

Basu S, Bundick B (2017) Uncertainty shocks in a model of effective demand. Econometrica 85:937-958

Benigno G, Benigno P, Nisticó (2012) Risk, monetary policy and the exchange rate. NBER Macroecon Annu 26(1):247-309

Berger T, Grabert S, Kempa B (2016) Global and country-specific output growth uncertainty and macroeconomic performance. Oxf Bull Econ Stat 78(5):694-716

Bernanke BS (1983) Irreversibility, uncertainty and cyclical investment. Quart J Econ 98(1):85-106

Bhattarai S, Chatterjee A, Park WY (2020) Global spillover effects of US uncertainty. J Monet Econ 14:71-89

Blei DM, Ng AY, Jordan MI (2003) Latent Dirichlet allocation. J Mach Learn Res 3:993-1022

Blei DM (2012) Probabilistic topic models. Commun ACM 55(4):77-84

Bloom N (2009) The impact of uncertainty shocks. Econometrica 77(3):623-685

Bonciani D, Ricci M (2018) The global effects of global risk and uncertainty. European Central Bank Working Paper No. 2179

Born B, Pfeifer J (2014) Policy risk and the business cycle. J Monet Econ 68:68-85

Busse M, Hefeker C (2007) Political risk, institutions and foreign direct investment. Eur J Polit Econ 23(2):397-415

Caggiano G, Castelnuovo E, Groshenny N (2014) Uncertainty shocks and unemployment dynamics: an analysis of post-WWII U.S. recessions. J Monet Econ 67:78-92

Caggiano G, Castelnuovo E, Figueres JM (2017) Economic policy uncertainty and unemployment in the United States: a nonlinear approach. Econ Lett 151:31-34

Caggiano G, Castelnuovo E, Figueres JM (2020) Economic policy uncertainty spillovers in booms and busts. Oxf Bull Econ Stat 82:125-155

Caldara D, Fuentes-Albero C, Gilchrist S, Zakrajšek E (2016) The macroeconomic impact of financial and uncertainty shocks. Eur Econ Rev 88:185-207

Carrière-Swallow Y, Cèpedes LF (2013) The impact of uncertainty shocks in emerging countries. J Int Econ 90:316-325

Carriero A, Clark TE, Marcellino M (2018a) Measuring uncertainty and its impacts on the economy. Rev Econ Stat 100(5):799-815

Carriero A, Clark TE, Marcellino M (2018b) Endogenous Uncertainty. Federal Reserve Bank of Cleveland Working Paper No. 18-05

Carriero, A., Clark, T.E., Marcellino, M., 2019. The identifying information in vector autoregressions with time-varying volatilities: An application to endogenous uncertainty. Federal Reserve Bank of Cleveland Working Paper 18-05

Carroll CD (1997) Buffer-stock saving and the life cycle/permanent income hypothesis. Q J Econ 112(1):155

Cascaldi-Garcia D, Galvao AB (2018) News and Uncertainty Shocks. International Finance Discussion Papers 1240

Castelnuovo E, Tran TD (2017) Google it up! A google trends-based uncertainty index for the United States and Australia. Econ Lett 161:149-153

Cerda R, Silva A, Valente J (2018) Impact of economic uncertainty in a small open economy: the case of Chile. Appl Econ 50(26):2894-2908

Cesa-Bianchi A, Pesaran MH, Rebucci A (2018) Uncertainty and economic activity: a multi-country perspective. NBER Working Paper No. w24325

Chang J, Gerrish S, Wang C, Boyd-Graber J, Blei DM (2009) Reading tea leaves: how humans interpret topic models. In: Proceedings of the 22nd international conference on neural information processing systems, pp 288-296 
Chatterjee P (2018) Asymmetric impact of uncertainty in recessions - are emerging countries more vulnerable? Stud Nonlinear Dyn Econom 23(2):1-27

Chatterjee P (2019) Uncertainty shocks, financial frictions and business cycle asymmetries across countries. University of New South Wales, mimeo

Cheng CHJ (2017) Effects of foreign and domestic economic policy uncertainty shocks on South Korea. J Asian Econ 51:1-11

Christiano LJ, Motto R, Rostagno M (2014) Risk shocks. Am Econ Rev 104(1):27-65

Choi S, Loungani P (2015) Uncertainty and unemployment: effects of aggregate and sectoral channels. J Macroecon 46:344-358

Colombo V (2013) Economic policy uncertainty in the US: does it matter for the Euro area? Econ Lett 121:39-42

Creal DD, Wu JC (2017) Monetary policy uncertainty and economic fluctuations. Int Econ Rev 58(4):13171354

Cuaresma JC, Huber F, Onorante L (2019) The macroeconomic effects of international uncertainty. European Central Bank Working Paper No. 2302

Davis SJ (2016) An index of global economic policy uncertainty. NBER Working Paper No. 22740

Favero C, Giavazzi F (2008) Should the Euro area be run as a closed economy? Am Econ Rev 98(2):138-145

Fernàndez-Villaverde J, Guerrón-Quintana P, Rubio-Ramírez JF, Uribe M (2011) Risk matters: the real effects of volatility shocks. Am Econ Rev 101(6):2530-61

FOMC (Federal Open Market Committee) (2009) Minutes of the Federal Open Market Committee, December 15-16, 2009

Forbes KJ, Warnock FE (2012) Capital flow waves: surges, stops, flight, and retrenchment. J Int Econ $88(2): 235-251$

Forbes K (2016) Uncertainty about uncertainty. Technical Report, Speech to be given by Kristin Forbes, External MPC Member, at J.P. Morgan Cazenove Best of British Conference, London

Gilchrist S, Sim JW, Zakrajšek E (2014) Uncertainty, financial frictions and investment dynamics. NBER Working Paper No. 20038

Griffiths TL, Steyvers M (2004) Finding scientific topics. Proc Natl Acad Sci 101:5228-5235

Guglielminetti E (2016) The labor market channel of macroeconomic uncertainty. Bank of Italy Working Paper No. 1068

Haddow A, Hare C, Hooley J, Shakir T (2013) Macroeconomic uncertainty: what is it, how can we measure it and why does it matter? Bank Engl Q Bull 53(2):100-109

Handley K (2014) Exporting under trade policy uncertainty: theory and evidence. University of Michigan Working Paper

Handley K, Limão N (2012) Trade and investment under policy uncertainty: theory and firm evidence. NBER Working Paper No. 17790

Huang Z, Tong C, Qui H, Shen Y (2018) The spillover of macroeconomic uncertainty between the US and China. Econ Lett 171(5):123-127

Husted L, Rogers J, Sun B (2020) Monetary policy uncertainty. J Monet Econ 115:20-36

Hlaing SW, Kakinaka M (2019) Global uncertainty and capital flows: any difference between foreign direct investment and portfolio investment? Appl Econ Lett 3

IMF (2013) Hopes, realities, risks. World Economic Outlook, April 2013

Jurardo K, Ludvigson SC, Ng S (2015) Measuring uncertainty. Am Econ Rev 105(3):1177-1216

Julio B, Yook Y (2016) Policy uncertainty, irreversibility and cross-border flows of capital. J Int Econ 103:13-26

Kang W, Ratti RA, Vespignani J (2019) Impact of global uncertainty on the global economy and large developed and developing economies. Appl Econ 52:2392-2407

Kilian L (1998) Small-sample confidence intervals of impulse response functions. Rev Econ Stat 80(2):218230

Kimball MS (1990) Precautionary saving in the small and in the large. Econometrica 58(1):53-73

Knotek ES, Khan S (2011) How do households respond to uncertainty shocks? Kansas City Federal Reserve Board Economic Review

Kozeniauskas N, Orlik A, Veldkamp L (2018) What are uncertainty shocks? J Monet Econ 100:1-15

Larsen VH (2021) Components of uncertainty. Int Econ Rev (forthcoming)

Leduc S, Liu Z (2016) Uncertainty shocks are aggregate demand shocks. J Monet Econ 82:20-35

Londono JM, Ma S, Wilson BA (2019) Quantifying the impact of foreign economic uncertainty on the US economy. FEDS Notes 
Luangaram P, Sethapramote Y (2020) Capital flows and political conflicts: Evidence from Thailand. Econ Peace Secur J 15(2):83-100

Ludvigson SC, Ma S, Ng S (forthcoming) Am Econ J Macroecon

Luk P (2017) Global banks, International business cycles and monetary policy. Hong Kong Baptist University Working Paper

Luk P, Cheng M, Ng P, Wong K (2017) Economic policy uncertainty spillovers in small open economies: the case of Hong Kong

McDonald R, Siegel D (1986) The value of waiting to invest. Q J Econ 101(4):707-727

Meinen P, Roehe O (2017) On measuring uncertainty and its impact on investment: cross-country evidence from the Euro area. Eur Econ Rev 92:161-179

Miescu MS (2019) Uncertainty shocks in emerging economies: a global to local approach for identification. Lancaster University Economics Working Paper Series No. 2019/017

Moore A (2017) Measuring economic uncertainty and its effects. Econ Rec 93:550-575

Mumtaz H (2018) Does uncertainty affect real activity? Evidence from state-level data. Econ Lett 167:127130

Mumtaz H, Theodoridis K (2017) Common and country specific economic uncertainty. J Int Econ 105(C):205-216

Mumtaz H, Musso A (2018) The evolving impact of global, region-specific and country-specific uncertainty. European Central Bank Working Paper No. 2147

Mumtaz H, Surico P (2018) Policy uncertainty and aggregate fluctuations. J Appl Econom 33(3):319-331

Mumtaz H, Theodoridis K (2015) The international transmission of volatility shocks: an empirical analysis. J Eur Econ Assoc 13(3):512-533

Novy D, Taylor AM (2014) Trade and uncertainty, NBER Working Paper No. 19941

Orlik A, Veldkamp L (2014) Understanding uncertainty shocks and the role of black swans. NBER Working Paper No. w20445

Phillips KL, Spencer DE (2011) Bootstrapping structura VARs: avoiding a potential bias in confidence intervals for impulse response functions. J Macroecon 33(4):582-594

Razin A, Sadka E, Yuen C (1998) A pecking order of capital flows and international tax principles. J Int Econ 44:45-68

Redl C (2017) The impact of uncertainty shocks in the United Kingdom. Bank of England Working Paper No. 695

Rey H (2013) Dilemma not trilemma: the global financial cycle and monetary policy independence. Federal Reserve Bank of Kansas City Economic Policy Symposium

Ricco G, Callegari G, Cimadomo J (2016) Signals from the government: policy uncertainty and the transmission of fiscal shocks. J Monet Econ 82:107-118

Rich R, Tracy J (2010) The relationships among expected inflation, disagreement and uncertainty: evidence from matched point and density forecasts. Rev Econ Stat 92(1):200-207

Rossi B, Sekhposyan T (2015) Macroeconomic uncertainty indices based on nowcast and forecast error distributions. Am Econ Rev (Paper and Proceedings) 105(5):650-655

Scotti C (2016) Surprise and uncertainty indexes: real-time aggregation of real-activity macro surprises. J Monet Econ 82:1-19

Sims C, Stock J, Watson M (1990) Inference in linear time series models with some unit roots. Econometrica 58(1):113-144

Wallach HM, Murray I, Salakhutdinov R, Mimno D (2009) Evaluation methods for topic models. In: Proceedings of the 26th annual international conference on machine learning. ACM, Harvard, pp 1105-1112

Publisher's Note Springer Nature remains neutral with regard to jurisdictional claims in published maps and institutional affiliations. 